People and Their Monuments in the Upper Clyde Valley 


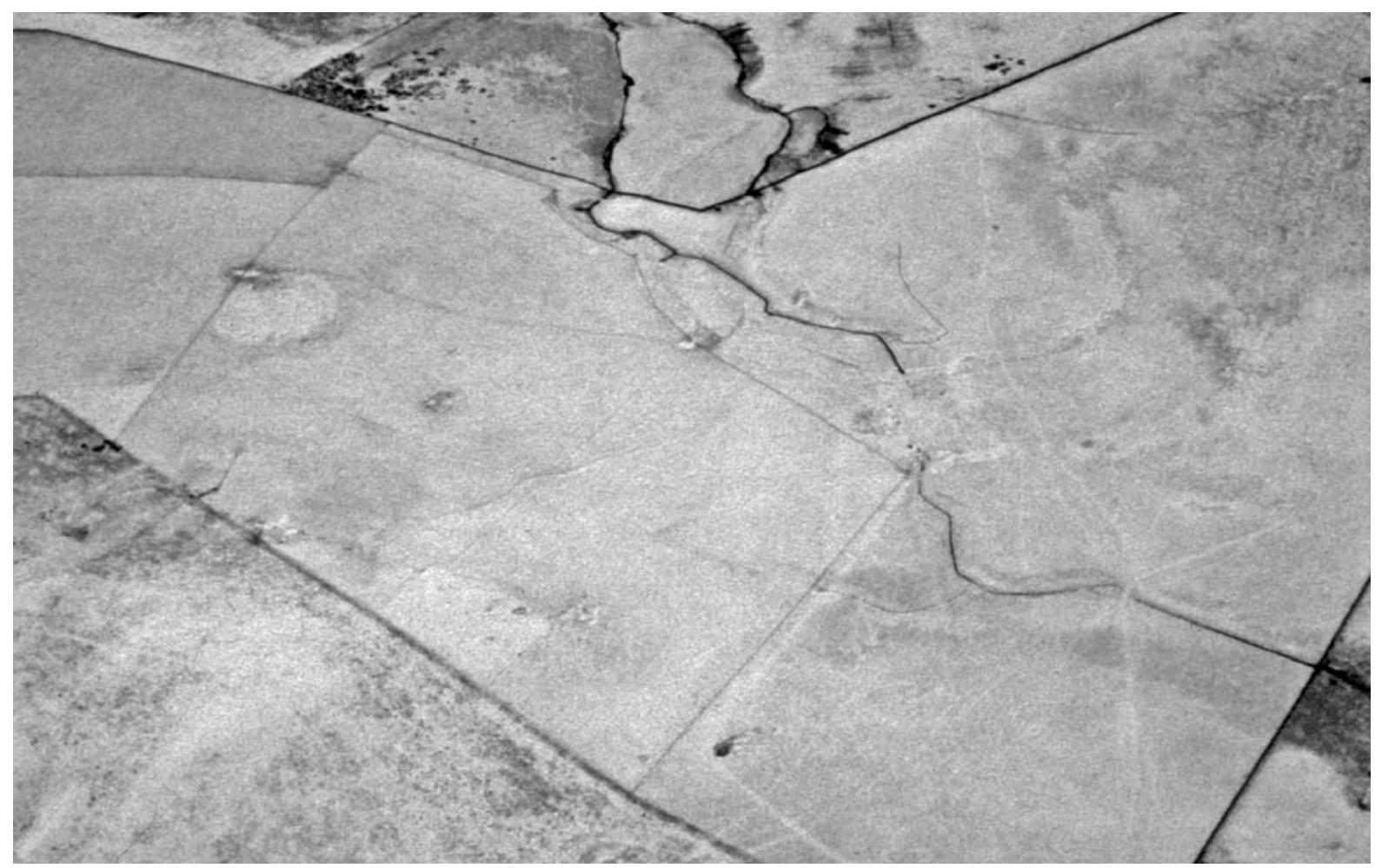

Aerial view of the enclosures at Blackshouse Burn and the Meadowflatts enclosure (to the left of frame) under snow (copyright W S Hanson) 


\title{
People and Their Monuments in the Upper Clyde Valley
}

\author{
A programme of survey, field walking and \\ trial excavation in the environs of the Blackshouse Burn \\ Neolithic enclosure, South Lanarkshire, 1998-99
}

by Olivia Lelong, ${ }^{1}$ Chris Barrowman, ${ }^{2}$

Mike Donnelly, ${ }^{3}$ the late Jerry Hamer and Lorna Sharpe ${ }^{4}$

${ }^{1}$ GUARD, University of Glasgow, Gregory Building, Lilybank Gardens, Glasgow G12 8QQ

${ }^{2} 16$ Eorodale, Port of Ness, Isle of Lewis HS2 0TR

${ }^{3} 175$ Wilton Street, Glasgow G20 6DF

${ }^{4}$ Department of Archaeology, University of Glasgow, Gregory Building, Lilybank Gardens, Glasgow G12 8QQ

with a contribution by Torben Bjarke Ballin

Illustrations by Caitlin Evans and John Arthur

Scottish Archaeological Internet Report 14, 2005 www.sair.org.uk 
Published by the Society of Antiquaries of Scotland, www.socantscot.org with Historic Scotland and the Council for British Archaeology

Editors $\quad$ Colin Wallace and Debra Barrie

Produced by Archetype Information Technology Ltd, www.archetype-it.com

ISBN: 0903903830

ISSN: $1473-3803$

Requests for permission to reproduce material from a SAIR report should be sent to the Director of the Society of Antiquaries of Scotland, as well as to the author, illustrator, photographer or other copyright holder.

Copyright in any of the Scottish Archaeological Internet Reports series rests with the SAIR Consortium and the individual authors.

Ordnance Survey data reproduced from OS 1:10,000 scale NS94SE and NS94SW maps and OS

Landranger 1:50,000 scale 71 map, by permission of Ordnance Survey on behalf of The Controller of Her Majesty's Stationery Office. Crown copyright 1978. All rights reserved.

The consent does not extend to copying for general distribution, advertising or promotional purposes, the creation of new collective works or resale. 


\section{Contents}

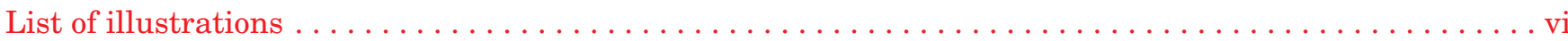

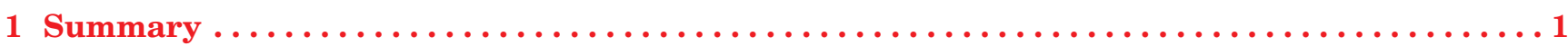

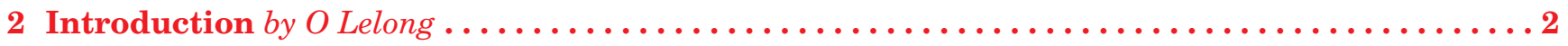

3 The Context of the Blackshouse Burn Environs Project by $O$ Lelong ................. 3

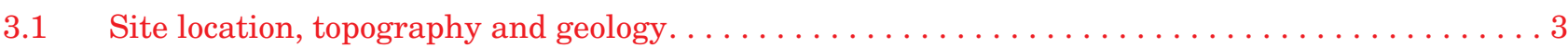

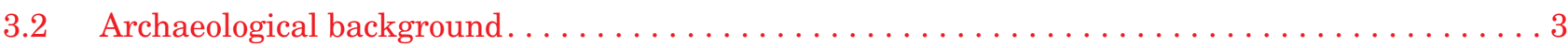

4 Aims, Objectives and Methodology by O Lelong, with C Barrowman, M Donnelly,

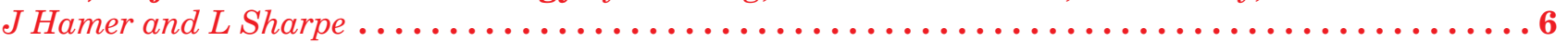

4.1 General aims . . . . . . . . . . . . . . . . . . . . . . . . . . . . . . 6

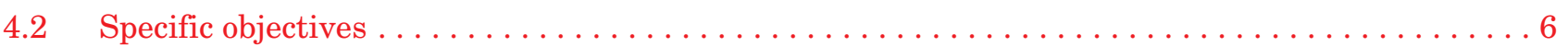

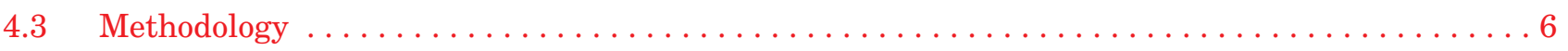

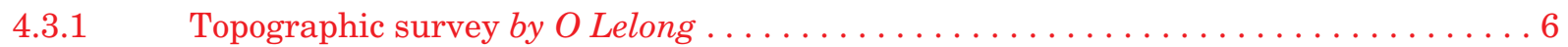

4.3.2 Geophysical survey by J Hamer and $L$ Sharpe . . . . . . . . . . . . . . . . 6

4.3.3 Field walking by $C$ Barrowman and $M$ Donnelly ....................... 7

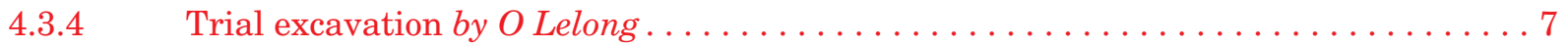

5 The Results of the Blackshouse Burn Environs Project ..................... 9

5.1 The uplands: topographic and geophysical surveys by $O$ Lelong, J Hamer and L Sharpe . . . . . . 9

5.1.1 Blackshouse Burn and Meadowflatts . . . . . . . . . . . . . . . . . . . . 9

$5.1 .2 \quad$ Chester Hill. . . . . . . . . . . . . . . . . . . . . . . . . . . . . . . . . . . . . . . 12

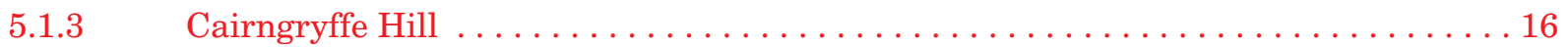

$5.1 .4 \quad$ Swaites Hill. . . . . . . . . . . . . . . . . . . . . . . . . . . . . . . . . . 17

5.2 The lower slopes and valleys: field walking and trial excavation

by $M$ Donnelly and $O$ Lelong . . . . . . . . . . . . . . . . . . . . . . . . . . . . . . . 19

5.2.1 The results of field walking by M Donnelly, with $T$ Ballin . . . . . . . . . . . . 19

5.2.2 Trial excavation at Carmichael . . . . . . . . . . . . . . . . . . . . . . 22

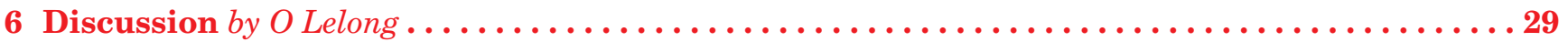

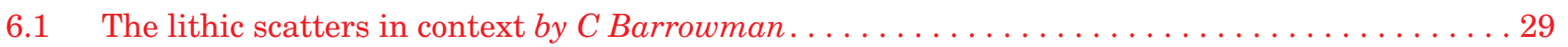

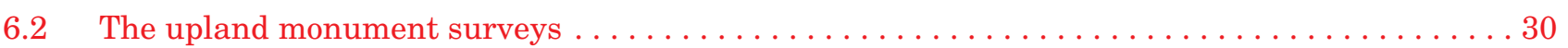

6.3 Prehistoric activity on the lower slopes and in the valleys by $C$ Barrowman ............. 31

7 Conclusions from the Blackshouse Burn Environs Project by $O$ Lelong ................ 32

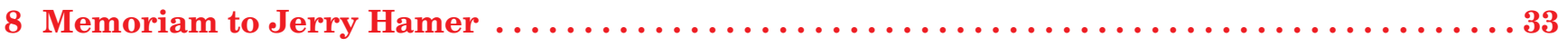

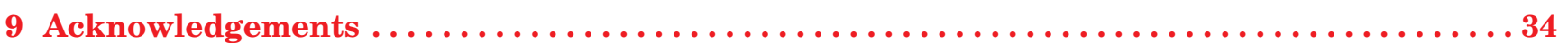

10 References....................................................... 


\section{List of illustrations}

Frontispiece - aerial view of the enclosures at Blackshouse Burn and the Meadowflatts enclosure (to the left of frame) under snow (copyright W S Hanson)

1 Location map, showing the extent of the survey area and fields walked during the Blackshouse Burn Environs Project . . . . . . . . . . . . . . . . . . . 4

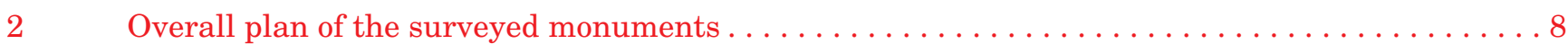

3 Survey plan of the Blackshouse Burn and Meadowflatts monuments . . . . . . . . . . . 10

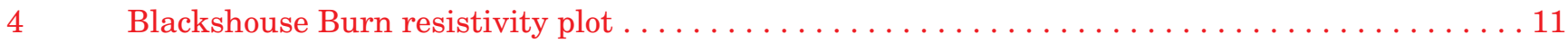

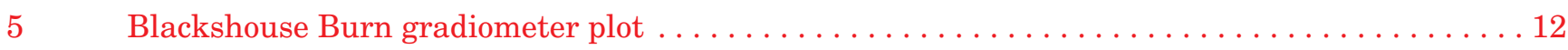

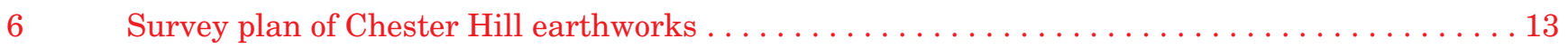

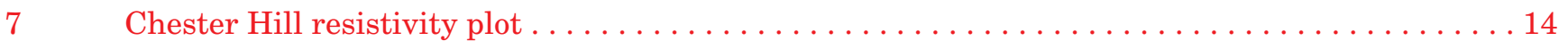

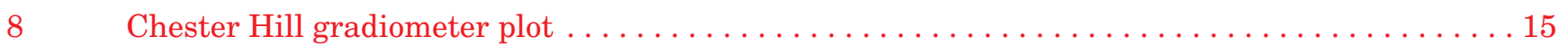

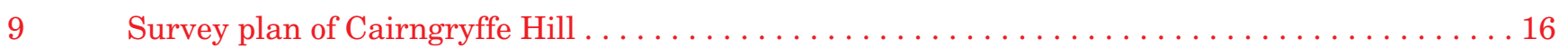

$10 \quad$ Survey plan of Swaites Hill . . . . . . . . . . . . . . . . . . . . . . . . . 18

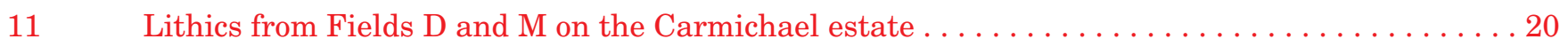

$12 \quad$ Location of trial trenches and lithic scatter at Carmichael . . . . . . . . . . . . . . . . . . . . . . . 23

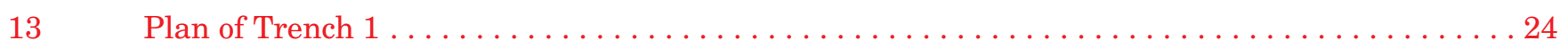

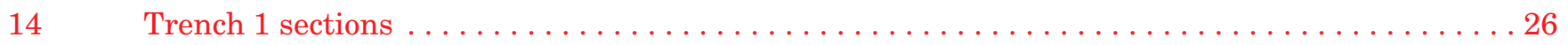

15 Trench 3 plan and sections, with plan and section of Trench 1 feature $028 \ldots \ldots \ldots \ldots \ldots 27$ 


\section{Summary}

This report sets out the results of a programme of topographic survey, geophysical survey, field walking and trial excavation, carried out in 1998-99 and funded by Historic Scotland, in and around an extensive upland prehistoric landscape in the Upper Clyde Valley. It was designed to build on the results of limited excavation of a large, late Neolithic enclosure at Blackshouse Burn, South Lanarkshire (centred at NGR NS 9528 4046) and preliminary survey of nearby monuments undertaken in the $1980 \mathrm{~s}$, and to identify and characterize prehistoric settlement in the adjacent valleys through field walking.

Topographic survey of the enclosures at Blackshouse Burn, Meadowflatts and Chester Hill, and of hut circles, clearance cairns and a possible ring cairn on Cairngryffe and Swaites Hills, recorded a complex ritual and domestic landscape: evidence of the long- standing prehistoric occupation of the Pettinain Uplands. The geophysical survey of Chester Hill enclosure found traces of internal structures and quarry scoop, while geophysical survey of part of the large Blackshouse Burn monument and smaller adjacent enclosure found evidence for a curvilinear feature in the large enclosure and a possible screen in its entrance.

The systematic examination of ploughed fields in the valleys to the west and south-west of the upland monument complex discovered several concentrations of lithics, most notably evidence of late Mesolithic tool production and late Neolithic to early Bronze Age tool production and domestic activity. Trial trenches excavated over a late Mesolithic cluster at Carmichael found a knapping floor and several structural features. 


\section{Introduction by $O$ Lelong}

The Blackshouse Burn Environs Project was designed to investigate and record through survey a complex of upland prehistoric archaeological remains and to examine the adjacent valleys for evidence of prehistoric settlement. The project was conceived as a landscape study which would build on the results of limited excavation and survey carried out in the 1980s under the direction of Peter Hill on behalf of Historic Scotland's predecessor department (SDD/HBM), the results of which were published in the Proceedings of the Society of Antiquaries of Scotland (Lelong \& Pollard 1998a).

In that earlier programme of work a very large late Neolithic sub-circular enclosure in an upland basin at Blackshouse Burn (centred at NGR NS 95284046 ) and a smaller adjacent one were investigated through trial excavation. The 1980s fieldwork also included preliminary survey of the ridge that half-encircles the upland basin, recording the presence and general locations of hut circles, clearance cairns and burial cairns, although not in detail.

The density and monumentality of the archaeological remains on these uplands indicate the area's importance to those living in or travelling to the Upper Clyde Valley during prehistory. The topographic and geophysical surveys, field walking and trial excavation undertaken as part of the project reported upon here, along with the results of the 1980s fieldwork, have produced a more informed understanding of the character and development of the monuments on the uplands and of how the surrounding landscape was inhabited.

The Blackshouse Burn Environs Project coincided and collaborated with the much larger Upper Clyde Valley Landscape Project, being carried out by Professor Bill Hanson and Lorna Sharpe of the University of Glasgow (Hanson \& Sharpe in prep; Sharpe forthcoming), and the complementary relationship between the two projects has added value to the results of both. 


\section{The Context of the Blackshouse Burn Environs Project by $O$ Lelong}

\subsection{Site location, topography and geology}

The survey area lies in the Upper Clyde Valley, to the west and south-west of a deep bend in the river. It includes a crescent-shaped massif; a small, nameless valley immediately west of the uplands, through which the A73 now runs; the valley of the Glade Burn to the north of Tinto Hill, and the area around Carmichael village, to the south-west of Carmichael Hill (see Illus 1). The massif is a broad ridge that rises to four crests - Chester Hill, Swaites Hill, Cairngryffe Hill and Westraw Hill - and curves around the east side of a broad, boggy, upland basin. The local antiquarian, David Christison, termed the massif 'Pettinain Hill' after a local village (Christison 1890, 324-5); his useful term, employed in recent publications (Lelong \& Pollard 1998a; Lelong \& Pollard 1998b), has been adapted here to 'Pettinain Uplands' (to distinguish the massif from the hills that comprise it). The Blackshouse Burn springs up in the basin and flows down the west side of the Pettinain Uplands into the adjacent valley.

The topographic and geophysical surveys focused on monuments on the Pettinain Uplands. Field walking took place on ploughed fields in the adjacent valleys, with trial trenching over a lithic scatter at Carmichael village (see Illus 1). Most of the survey area belongs to the Carmichael estate, although the topographic survey also extended onto the neighbouring farms of Meadowflatts and Swaites.

The solid geology of the Pettinain Uplands consists of stratified metamorphosed sedimentary rocks of Silurian age, mainly conglomerate with intervening sandstones, overlain by patches of greywacke, with felsite making up Cairngryffe Hill; in the valleys to the south and west, the solid geology consists of quartzite conglomerate also of Silurian age. Overlying the rock on the uplands and in the valleys is a thin, consolidated, glacially deposited till, mainly derived from the Silurian sediments and including lumps of sandstone (British Geological Survey 1:63,360 map, Sheet 23, Solid and Drift).

\subsection{Archaeological background}

Spread across the ridge and basin of the Pettinain Uplands is a complex prehistoric landscape, comprising ritual, domestic and possibly defensive elements. The ridge is thickly sprinkled with upstanding archaeological remains, including the double-banked circular enclosure on Chester Hill, the smaller enclosure at Meadowflatts and the cairns, hut circles and other features on Cairngryffe
Hill and Swaites Hill, all recorded in this survey. In addition to these is the Hero's Cairn, which was excavated and found to be a robbed cairn containing a disturbed cist, with part of a Food Vessel and cremation inside it (Stevenson 1976; RCAHMS 1978, 64, no 106[1]). Also scattered along the ridge are at least 26 other cairns recorded by the Royal Commission (RCAHMS 1978, 64-5, no 106[2-8]). The ridge defines a natural amphitheatre, in which lies the Blackshouse Burn enclosures as well as several small cairns inside and to the west of them.

In 1985 and 1986, limited excavations carried out on both the large, sub-circular enclosure at Blackshouse Burn and the smaller, adjacent one (Lelong \& Pollard 1998a) established something of their character and date. The large enclosure was built around the double heads of the Blackshouse Burn, which exits it on the west. The enclosure was originally defined by a double ring of substantial timber posts on either side of a rubble bank. The bank had later been extended to lap around the bases of the posts; after they decayed, more stone was added to cap the bank above the post holes. Waterlogged conditions beneath the bank had preserved the stumps of oak posts in the excavated section, and one of these was dated to 2697-2453 cal BC (GU-1983: Lelong \& Pollard 1998a, 42).

While no dating evidence was recovered from the bank of the smaller enclosure, this proved to have been built just within an ancient bog. Several neatly defined pits or ditches had first been dug into the peat using mattocks, and then a stone ring (possibly a double-skinned drystone wall) had been built above it.

Pollen from peat columns taken from the bog indicated that the local birch and hazel woodland began to decline after $7500 \mathrm{BP}$, to be replaced by a more open, grassy landscape, probably as a result of human impact (Ramsay 1998, 37-40). It is thought that Mesolithic hunters may have cleared the local vegetation in order to flush out game. The scale of and enormous effort involved in building the enclosures suggest that their construction formalized a place long perceived as a natural monument (see Bradley 1991, 136) which had perhaps been a focus for hunting and other, ritual activity over many generations since the Mesolithic. Clearly the basin's significance continued and deepened during the Neolithic. The clear references to water in the monuments could indicate a root in traditions of transhumance to the uplands, where sources of water for stock would have been at a premium (Lelong \& Pollard 1998a, 47-50).

The enclosures are the most monumental of a number of significant structures on the upland that 


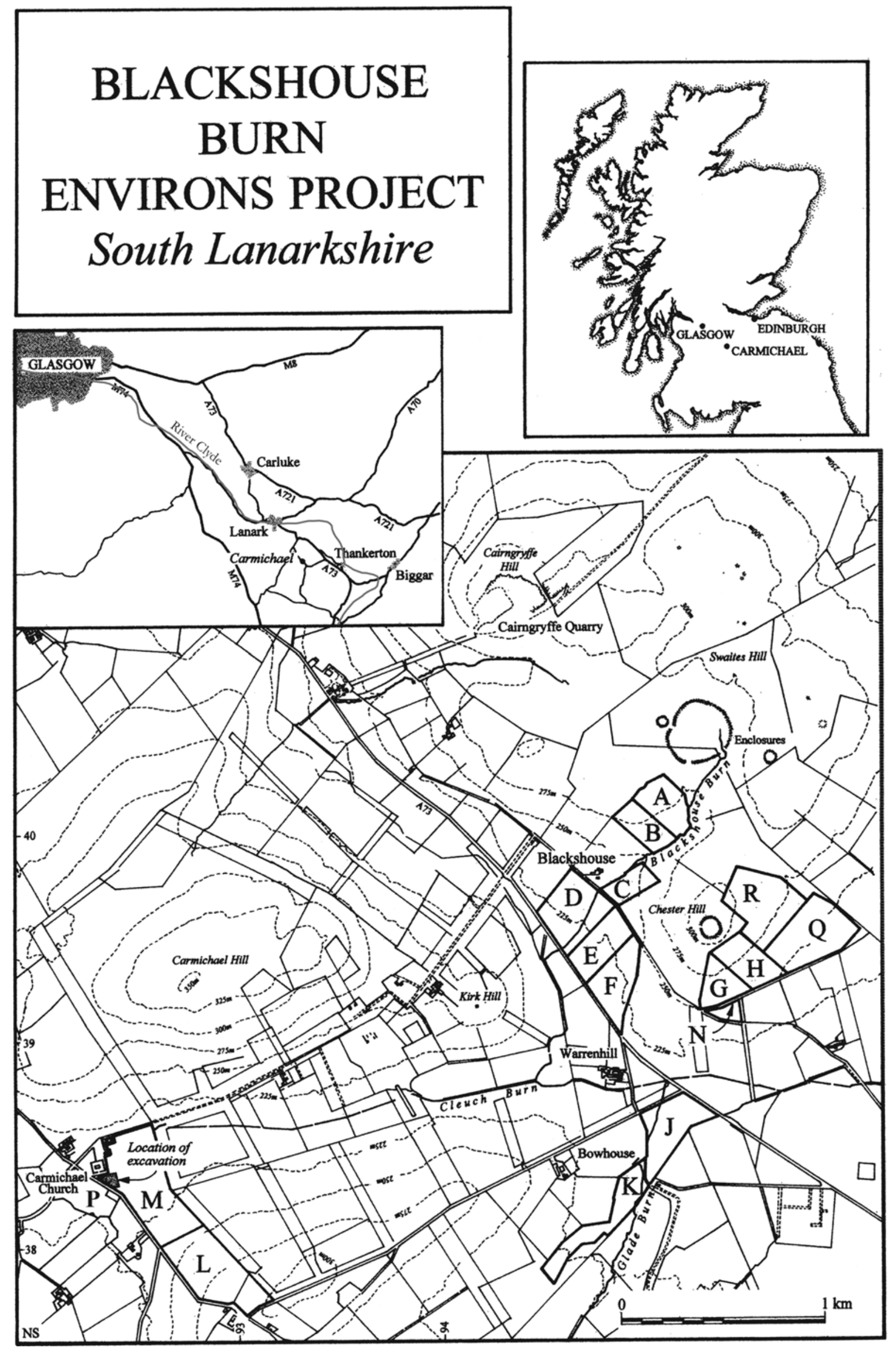

Illus 1 Location map, showing the extent of the survey area and fields walked during the Blackshouse Burn Environs Project 
indicate its continuing importance throughout prehistory. Among the others was a Bronze Age ring cairn on Cairngryffe Hill, now destroyed by quarrying but subjected to rescue excavation during the 1980s under the direction of Mary Kemp-Clarke (Lelong \& Pollard 1998b). It proved to be a multiphase monument, with evidence for early Neolithic activity followed by early Bronze Age timber and stone rings associated with cremations and dated by radiocarbon to $1890-1630$ and $1910-1620$ cal BC (Beta-111006 and Beta-111007, respectively; Lelong \& Pollard 1998b, 119). This monument was superseded by a bank enclosing cremations in an imported felsite deposit, and the interior of the area was finally capped by a flat cairn. Later prehistoric monuments also occur at either end of the crescent-shaped ridge, with a later prehistoric hillfort on Cairngryffe Hill (since destroyed) (Childe 1941) and the circular banked enclosure on Chester Hill.

Recent and ongoing work in the surrounding area, particularly that carried out by the Upper Clyde Valley Landscape Project, Biggar Museum Trust, Historic Scotland and the Lanark and District Archaeological Society, has uncovered and clarified evidence for these monuments' wider prehistoric context. Field walking on Biggar Common in the wake of forestry planting has revealed a wealth of evidence for settlement and funerary practice from the late Mesolithic into the Bronze Age, including scatters of Neolithic pottery and lithics. Excavations as a result of field walking investigated an early Neolithic long mound that sealed a late Mesolithic stake-built structure and several early Neolithic bonfires, while excavations over artefact scatters have found traces of at least three early Neolithic structures (Sheridan 1989; Ward 1990; Ward 1991a; Ward 1991b; Ward 1992; Ward 1993; Ward 1995; Johnston 1997).

The region, particularly the area around Biggar, has produced an extraordinary concentration of stone axeheads (Clough \& Cummins 1988), suggesting the intensive movement of people or goods, or both, along the natural corridor formed by the river valley.

The Upper Clyde Valley Landscape Project, which carried out fieldwork from 1995 to 2001, has employed a diverse methodological approach in order to elucidate long-term patterns of land use and settlement from the Mesolithic onward. The methods, which include aerial reconnaissance, field walking, geophysical survey, trial excavation and documentary research, have identified numerous new sites and subjected others, including four of the five known henge monuments in the area, to more detailed investigation. While the results are still being prepared for publication, the project has already identified patterns of generally static, multi-phase settlement in the valleys with phases of agricultural and other activity on the uplands (Hanson \& Sharpe in prep; Sharpe forthcoming). 


\section{Aims, Objectives and Methodology by O Lelong, with contributions from $J$ Hamer, L Sharpe, $C$ Barrowman and $M$ Donnelly}

\subsection{General aims}

While these and other fieldwork projects in the Upper Clyde Valley have yielded a great deal of information about its prehistoric occupation, the Blackshouse Burn Environs Project was focused more specifically on the Pettinain Uplands and the valleys to the west and south-west. It aimed to enhance our understanding of prehistoric activity in this part of Upper Clydesdale and build upon that gained through the excavations at Blackshouse Burn and Cloburn Quarry in the 1980s, as well as the more recent work discussed above. More specifically, it aimed to identify traces of lowland activity that might be contemporary with the upland monuments and to complete the upland survey work begun in the 1980s.

\subsection{Specific objectives}

The objectives of the topographic survey were to produce detailed plans of the monuments at Chester Hill and Blackshouse Burn as well as the settlement remains on Cairngryffe Hill and Swaites Hill, in order to record and better understand their character, relationships and topographic context. The surveys were also designed to inform the future management of the sites, which were being damaged at the time of survey by stock, rabbits and vehicles.

The objectives of the geophysical survey were to subject the interior of Chester Hill fort and parts of the interiors of the large and small enclosures at Blackshouse Burn to electrical resistivity and magnetometry survey, in order to establish whether buried features such as ditches or hearths could be detected and to further understand the monuments' construction and use.

The objectives of the field walking were to identify scatters of lithics and other cultural material in ploughed fields in the valleys to the west of the Pettinain Uplands, which might indicate the locations of settlement contemporary with the monument complex; to plot the locations of any material found; and to collect and analyse it in order to better understand the nature and distribution of prehistoric settlement in the area.

The objectives of the trial trenching over the lithic scatter at Carmichael were to investigate whether or not features or deposits contemporary with the lithics survived beneath the ploughsoil; to sample and record any archaeological remains found; and to establish their character and (if possible) their date.

\subsection{Methodology}

\subsubsection{Topographic survey by O Lelong}

The topographic survey was carried out over 2 weeks in October 1998 and 3 days in February 1999 in wet and windy conditions. A Sokkia SET-5 total station EDM was used, with data logged electronically using a Psion datalogger equipped with SDR-5 software. The survey of Chester Hill was carried out from five stations established around the monument, and that of the Blackshouse Burn and Meadowflatt enclosures from a further three stations linked to those around Chester Hill. The survey of remains on Cairngryffe Hill and Swaites Hill was carried out from three stations. Fence lines and other features on the modern 1:10,000 Ordnance Survey map were included in the surveys in order to position and orientate them correctly within the National Grid.

The data were downloaded and processed using Liscad 4.0 software to produce contour maps, which were then exported to AutoCAD 14.0 for additional processing and artwork. Digitized map data were used in conjunction with surveyed fence lines to position the surveys within the National Grid.

\subsubsection{Geophysical survey by J Hamer and L Sharpe}

The geophysical surveys of Chester Hill fort and the Blackshouse Burn enclosures were carried out mainly over 8 days in October 1998 and concluded in December 1998. Both employed Geoscan Research Ltd instruments, including an electrical resistivity meter, a fluxgate gradiometer and data processing software. The resistivity meter (RM15), set for a twin electrode configuration, had an electrode separation of $0.5 \mathrm{~m}$, giving a measuring depth of $c 0.5 \mathrm{~m}$ below the ground surface. The fluxgate gradiometer (FM36) used for the magnetic surveys was capable of detection to about $1 \mathrm{~m}$ below the ground surface.

The Chester Hill surveys employed an $0.5 \mathrm{~m}$ sampling density, fine enough to detect any features expected to be present, such as hut circles and hearths. The data-recording capabilities of the instruments dictated that the resistivity grid size was $20 \mathrm{~m} \times 20 \mathrm{~m}$ and the gradiometer survey grids $20 \mathrm{~m} \times 10 \mathrm{~m}$.

The Chester Hill enclosure was surveyed over 5 days in October 1998 in variable weather conditions. Survey was somewhat impeded by the presence of tree stumps and mature trees and by the 
banks of the monument themselves. A significant amount of metal was encountered during the magnetic survey, almost entirely old wire fencing, perhaps indicating that the monument has at some point been part of a modern enclosure. Dummy readings were inserted over most of the larger tree stumps to simplify interpretation of the results.

At Chester Hill, the survey area did not include the banks of the monument, for two reasons. The banks are very steep and proved difficult and dangerous (to both instruments and operators) to negotiate. Also, resistance values proved extremely high over the banks, in some cases going beyond the scale of the meter. Such high readings were useful, showing that the banks can be assumed to be constructed of stone, freely draining and with little soil cover; however, they can prove problematic at the processing stage, masking more subtle features in Geoplot and necessitating the application of low-pass filters to the data.

At Blackshouse Burn, the geophysical surveys extended over part of the interior of the small enclosure and along a transect through the western entranceway and into the interior of the large enclosure. An evaluation survey was first carried out at a sampling density of $0.5 \mathrm{~m}$, using both instruments, and at this point the RM15 was chosen to continue the survey into the interior of the large enclosure. This survey had a reduced sampling density of $1 \mathrm{~m}$ to allow for maximum ground coverage, due to time constraints and the large area to be covered.

The data from the surveys were processed in Geoscan's Geoplot 3, the Windows version of the data processing package used with Geoscan instruments.

\subsubsection{Field walking by $C$ Barrowman and M Donnelly}

The field walking on the Carmichael Estate was originally scheduled to take place over the winter of 1998-99; the estate planned to plough fields as machinery was available over that period, and so after ploughing it should have been possible to let them weather for a few weeks prior to walking them. However, because of the extremely wet conditions in Lanarkshire over that winter, the autumn hay crop was not fully gathered until February, and so ploughing did not begin until then. As spring sowing was scheduled for early April, this left a relatively narrow window in which fields could be ploughed, allowed to weather and then walked.

Between late February and late March 1999, 16 fields on the estate were examined; these are marked on Illus 1. Some additional fields which would have been worthy of survey, including those between Fields B and D, were ploughed very late in the season and so there was not sufficient time to examine them before sowing took place.

An initial assessment of the archaeological potential of the 13 fields was carried out by the authors, both experienced field walkers with extensive knowledge of lithic material, in late February 1999. Each field was walked in 20-m transects and finds were left in place, marked by pin flags. This provided a general picture of the locations and densities of lithic material and informed the methodology for the more detailed field walking that followed.

Based on the results of the assessment, four fields were selected for more detailed examination: $\mathrm{A} / \mathrm{B}, \mathrm{D}$, $\mathrm{K}$ and $\mathrm{M}$. These were walked in tighter transects varying from $2 \mathrm{~m}$ (Fields $\mathrm{D}$ and $\mathrm{M}$ ) to $5 \mathrm{~m}$ (Fields $\mathrm{A}$ and $\mathrm{K}$ ) with larger teams of archaeologists, including many students with little or no experience of field walking or knowledge of lithic materials. The students were closely supervised by senior archaeologists. Finds were bagged and left in place, again marked with pin flags. The finds were then numbered, plotted using an EDM with each reading coded with the find number, and collected.

As the field walking was partly a training exercise for students, an assessment of the lithic material collected was carried out by Mike Donnelly, and pieces that were completely unworked were discarded. The remaining material was then subjected to a more thorough evaluation to establish the general character and date of the scatters.

\subsubsection{Trial excavation by $O$ Lelong}

Over the densest lithic scatter discovered during field walking (in Field M), trial excavation was carried out over 5 days in April 1999 to establish whether or not features or deposits related to the scatter survived beneath the ploughsoil. Four randomly placed, $2-\mathrm{m}^{2}$ test pits were dug by hand through the ploughsoil over the scatter to test its depth and the presence or absence of cultural material in it. Although no archaeological features or deposits were found in the test pits, several pieces of worked stone were recovered from the ploughsoil in all four pits, along with a large sherd of Impressed Ware in Test Pit D.

After this sampling, four trenches were opened over the scatter, using a JCB fitted with a flat-bladed bucket to strip away the ploughsoil in spits. The trenches are shown on Illus 13. The largest trench, Trench 1, was opened over the densest part of the scatter; it measured $24.5 \mathrm{~m}$ north/south and $3 \mathrm{~m}$ wide; an L-shaped extension along its east side measured $8 \mathrm{~m}$ long (east/west) and up to $7 \mathrm{~m}$ wide. Trench 2 was opened to the north of the scatter, and measured $12 \mathrm{~m}$ east/west by $3 \mathrm{~m}$. Trench 3 , opened over the south-east part of the scatter, measured $8 \mathrm{~m}$ north/south by $3 \mathrm{~m}$, and Trench 4, over the scatter's southern edge, measured $12.4 \mathrm{~m}$ east/west by $3 \mathrm{~m}$. The trenches were cleaned by hand, and archaeological features were subjected to sample excavation. After recording, the trenches were backfilled and the field was seeded. 


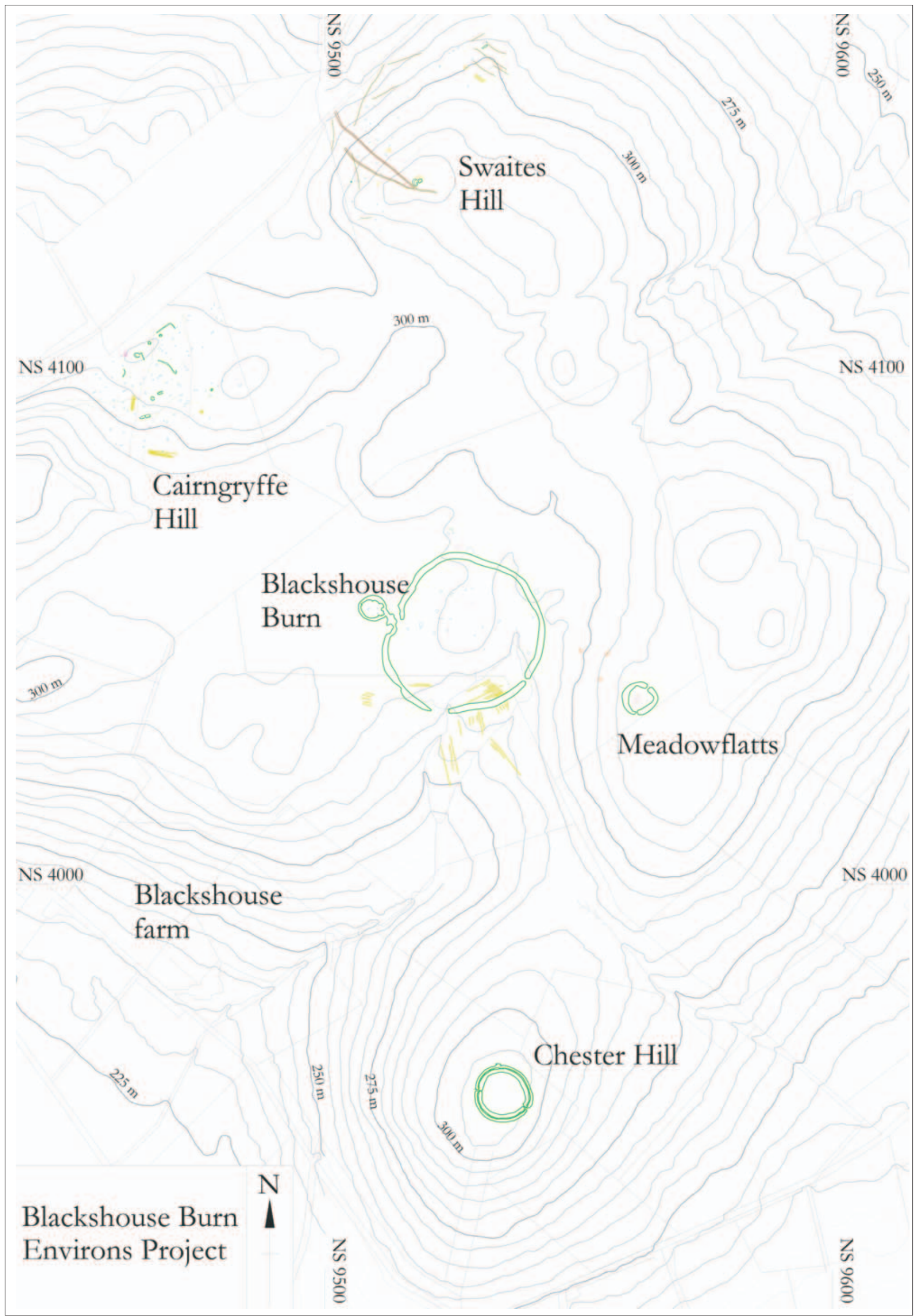

Illus 2 Overall plan of the surveyed monuments 


\section{The Results of the Blackshouse Burn Environs Project with contributions from M Donnelly, T Ballin, J Hamer and L Sharpe}

\subsection{The uplands: topographic and geophysical surveys by $O$ Lelong, $J$ Hamer and L Sharpe}

Illus 2 shows all of the monuments recorded by topographic survey on the Pettinain Uplands in relation to each other and to the terrain.

\subsubsection{Blackshouse Burn and Meadowflatts}

The topographic survey recorded the large and adjacent small enclosures in the upland basin at the head of the Blackshouse Burn, as well as the nearby enclosure of Meadowflatts (see Illus 3).

The large Blackshouse Burn enclosure lies in the south-east part of the basin in the Pettinain Uplands, between 295 and $285 \mathrm{~m}$ above OD (see Frontispiece). The enclosure is sub-circular, composed of fairly straight stretches of bank, and measures $300 \mathrm{~m}$ across (internally) east/west and $290 \mathrm{~m}$ north/south (see Illus 3). The bank itself measures between 7 and $14 \mathrm{~m}$ in width, but averages around $12 \mathrm{~m}$. Stone is apparent intermittently along its length, beneath turf. It is very low, standing to no more than $1.5 \mathrm{~m}$ high and in most places to under $1 \mathrm{~m}$, and is extremely irregular in appearance, with what appear to be robbing scoops along much of its length.

The 1980s excavations confirmed that the north-west sector of the bank had been robbed for stone, and along some stretches only the flanks survive intact (Lelong \& Pollard 1998a, 17). However, it seems unlikely that robbing could account for its unfinished appearance along its entire circumference. An early antiquarian describes 18th-century stone robbers finding cists containing urns inverted over cremations in the bank (Ferguson 1794, 39); it is possible therefore that later Bronze Age re-interpretation and re-use of the monument also involved disturbing its fabric and could partly account for its irregular appearance.

The bank is broken in three places: where the two prongs of the burn leave it on the south-east (Illus 3 , A) and south-west (Illus 3, B), and on the west (Illus 3 , C) beside the smaller enclosure. This western entrance (Illus 3, C) is perhaps the best defined. On the northern side of the entrance, the bank is slightly inturned, while to the south it turns outward and north-westward in an amorphous, hummocky mass to abut the smaller enclosure.
It is difficult to determine whether the breaks in the bank at the points (Illus 3, A and B) where the burn exits the enclosure were intended as entrances or whether they simply accommodated the burn; however, given the fact that the enclosure was deliberately built around the heads of the burn and these form the focus of the monument, the question may be irrelevant. The western break (Illus 3, B) is much wider than the eastern (Illus 3, A): 15 m compared to $3 \mathrm{~m}$. However, the bank to the west of break B peters out rather than ending abruptly. It is possible that stone robbing and/or past cattle erosion of the burn's banks are responsible for at least some of the break's width.

The northern part of the enclosure's interior comprises a plateau, $c 5 \mathrm{~m}$ higher than the southern and eastern parts through which the burns flow. Scattered over the plateau are $c 17$ small cairns between 2 and $6 \mathrm{~m}$ in diameter; another two lie to the east of the burn's eastern fork, and another two just outside the enclosure bank on the north-east and north (see Illus 3). Two of these investigated in the excavations (Illus 3, D) were discovered to be small heaps of stone lying on the old ground surface (Lelong \& Pollard 1998a, 30-1).

The smaller enclosure is defined by an even more irregular and hummocky, turf-covered stony bank. It is oval in plan, and measures $23 \mathrm{~m}$ north-west/ south-east by $18 \mathrm{~m}$ internally, with the bank between 2 and $5 \mathrm{~m}$ wide. The entrance is not easily definable, although breaks in the bank to either side of where it joins the large enclosure could have led into it. Inside it are at least five small cairns, no more than $1 \mathrm{~m}$ in diameter and $0.6 \mathrm{~m}$ high, visible as irregular, stony, turf-covered mounds. The interior of the enclosure is extremely boggy, in spite of drainage attempts (the excavation found ceramic drainage pipes, and a deep drainage ditch has been cut through the monument's south-west side).

The scale and internal topography of the large enclosure are such that at most places inside it, it is impossible to see all of the perimeter bank at once. Views from the enclosure to the surrounding landscape are also limited by its position in the basin. The curtain-like visual effect of the ridge to the south, east and north is continued along the west and south-west by Tinto, Kirk and Carmichael Hills. However, the Meadowflatts enclosure is visible, breaking the skyline, from most points within the large enclosure.

Both inside and outside the southern part of the 


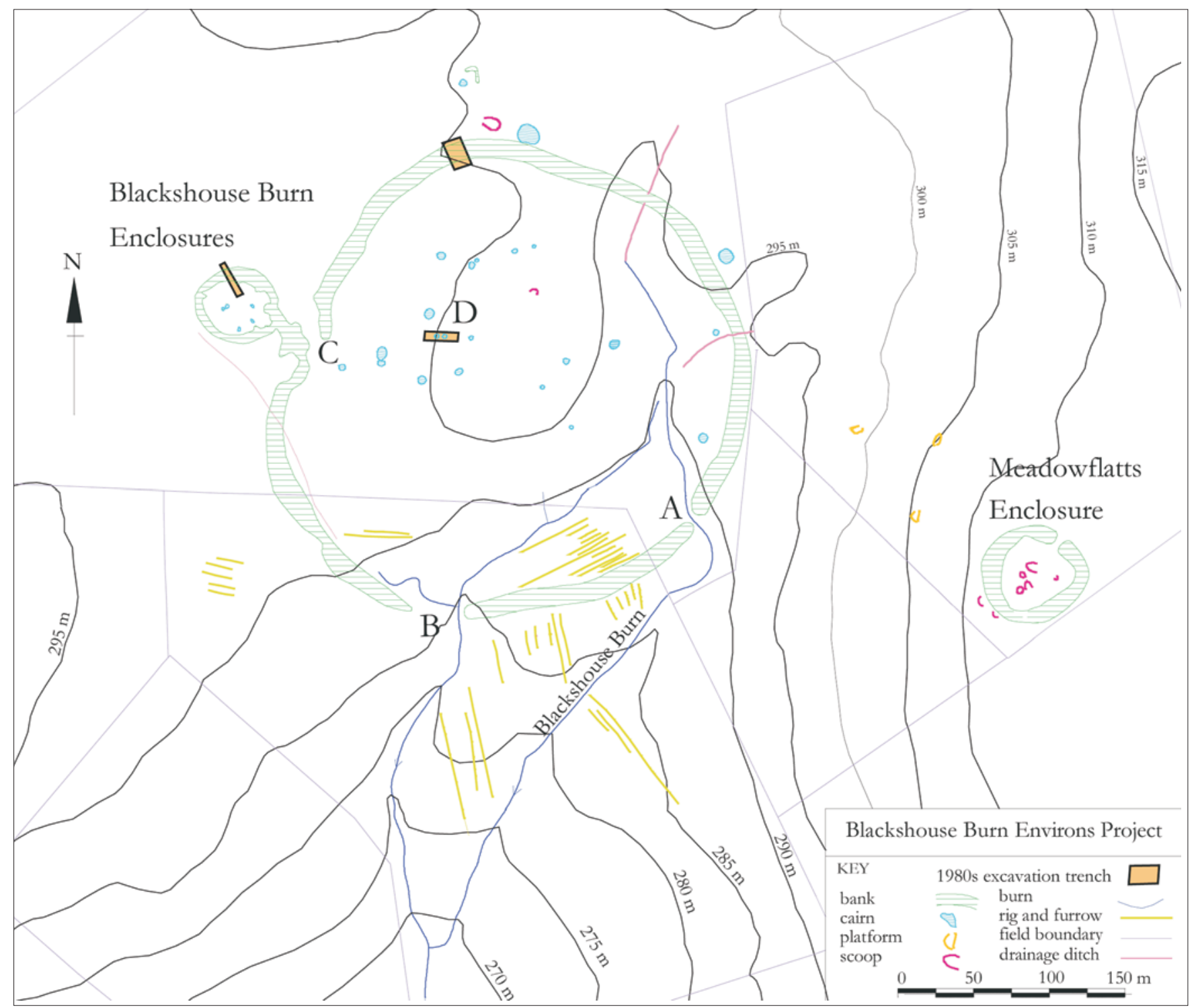

Illus 3 Survey plan of the Blackshouse Burn and Meadowflatts monuments

large enclosure are traces of rig and furrow cultivation (see Illus 3). The rigs visible on the ground at the time of survey, which measure between 0.6 and $2 \mathrm{~m}$ wide, represent only a fraction of those visible on aerial photographs; these have been transcribed by Lorna Sharpe as part of the Upper Clyde Valley Landscape Project.

The Meadowflatts enclosure (at $312 \mathrm{~m}$ above OD) is sub-circular in plan, measuring $c 24 \mathrm{~m}$ in diameter internally (see Illus 3). Its low, turf-covered bank measures between 3 and $5 \mathrm{~m}$ wide and, like the banks of the Blackshouse enclosures, it appears very irregular, possibly robbed. The bank is broken by a clear entrance on the NNE; a dip in the bank on the SSW probably represents disturbance.

Inside and outside to the south-west, several shallow scoops are visible; while seven were visible at the time of survey, more have been identified on aerial photographs taken when the monument was under snow (L Sharpe, pers comm). Those on the exterior appear to be later robbing pits which have intruded on the bank. Those on the interior may have been dug to quarry stone used to built the monument; alternatively, they could be pits containing cremations or other deposits, related to the prehistoric use of the monument.

The Blackshouse Burn enclosures sit on magnetically and resistively 'quiet' ground which provided an excellent background to the survey. Much of the ground on which the enclosures lie is poorly drained, preventing full resistivity coverage over areas of standing water. However, the damp and loosely compacted nature of the soil cover allowed good electrode contact over the rest of the area, ensuring a technically sound survey.

In the resistivity survey, attention focused on the entrance of the large enclosure and the area between that and the smaller western enclosure. This allowed known archaeology as well as an area containing no visible remains to be sampled. This 


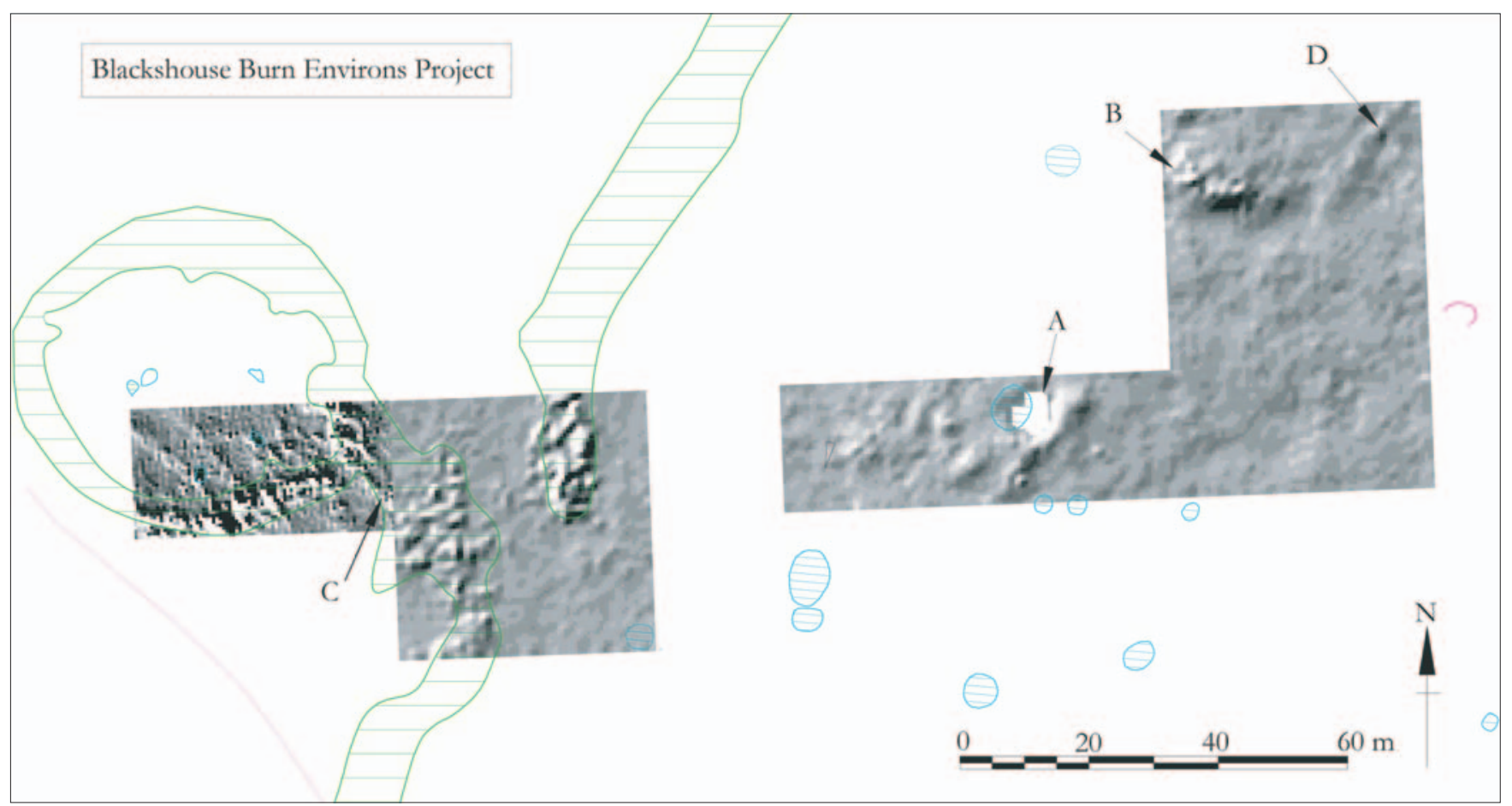

Illus 4 Blackshouse Burn resistivity plot

strategy also allowed evaluation of the instruments' performance, given the ground conditions.

Illus 4 shows the south-eastern arc of the smaller enclosure, with the bank terminals of the large enclosure appearing in the lower left of the plot. The smaller enclosure has a narrow but clearly defined entrance in the south-east, immediately west of the main enclosure entrance. There appears to be a linear anomaly which links the entrance of the small enclosure to the southern terminal of the large enclosure (Illus 4, C).

A number of linear features appear inside the small enclosure, trending north-west/south-east. These may represent traces of cultivation and seem to continue outside the enclosure where the plots reveal apparent breaches in the bank which are aligned with these linear features. The survey did not extend far enough to the south to allow the extent of the anomalies to be assessed. While no rig and furrow were visible in the rough, boggy ground at the time of survey, rig cultivation can be seen around both enclosures on aerial photographs. The linear feature (Illus 4, C) linking the two enclosures may also be associated with this cultivation, as it is trending in the same general direction.

The western entrance to the large enclosure is visible on the ground as a break in the extant banks. The resistivity plot, however, provides more information about the construction of the terminals. The high resistance response over the banks indicates their construction incorporates stone; this is consistent with excavated evidence for a rubble core (Lelong \& Pollard 1998a, 22-30). The plot also clearly shows that the terminals are staggered, with the northern terminal lying around $10 \mathrm{~m}$ to the east and inside the southern one.

Illus 4 also reveals the resistivity responses in part of the interior of the large enclosure. The gap in the survey data between the entrance and the rest of the interior marks the position of an area of standing water just inside and to the north of the entrance, which prevented resistivity survey. Another, smaller pond or spring is marked 'A' on Illus 4. The narrow high resistance area bordering the pond on the south-east side, together with associated, more subtle anomalies to the west of the water, indicates stone that may have been deliberately placed around the pond.

The other significant feature that appears in the resistance plot is in the top right corner, at the north-eastern edge of the survey area, marked B on Illus 4. The resistance plot shows the southern arc of a curvilinear feature. Its southern edge is marked by a low resistance area, which would usually be interpreted as a ditch or similar cut feature. This is echoed by an internal bank, which appears in the south-west of the arc as a high resistance feature on the plot. Finally, a linear feature (Illus 4, D) cuts the bank and ditch on the south-east and runs southwest, roughly aligning with the high resistance anomaly along the eastern side of the pond (Illus 4, A).

The only significant features that appear in the magnetic survey data (Illus 5) are the series of dipole anomalies set against an otherwise magnetically quiet background; they appear as dark spots, in some cases ringed with white. The dipoles are present in both enclosures and, in both cases, are 


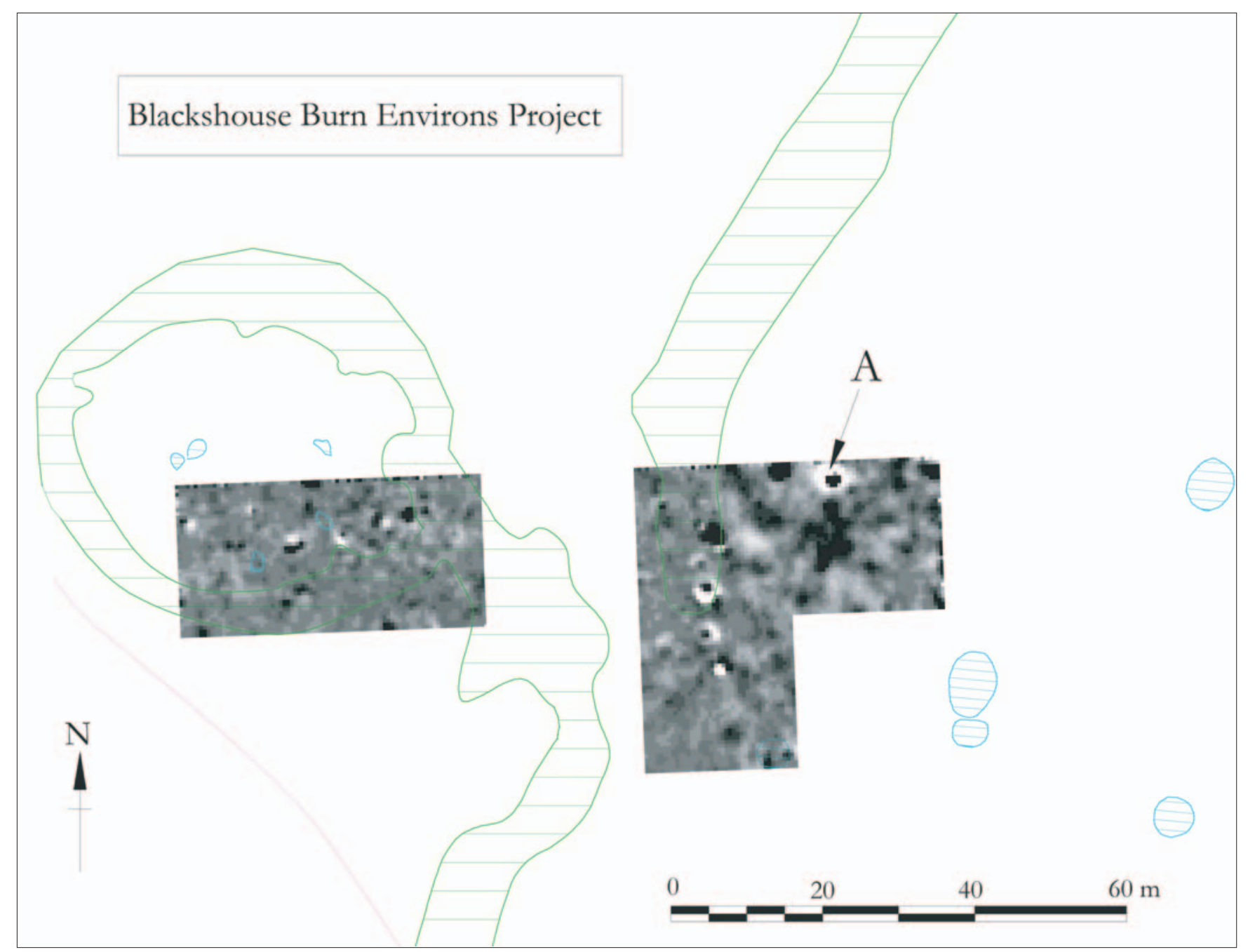

Illus 5 Blackshouse Burn gradiometer plot

associated with the resistivity anomalies recorded over the enclosure banks.

Dipoles are normally associated with areas of burning, especially in-situ burning, and are produced by fermentation reactions which also enhance the magnetic properties of soils. They also appear in response to the presence of metal objects, such as tines and other implements lost from farm machinery.

The dipoles associated with the enclosure banks could indicate the positions of cremations, such as those found beneath the enclosure's bank in the 18th century (Ferguson 1794, 39-40; Lelong and Pollard 1998a, 50). Alternatively, they may show the positions of post holes, possibly with waterlogged posts in situ such as those found in the north-west arc of the bank during the 1980s excavations (Lelong \& Pollard 1998a, 26-7). Illus 5 shows that these dipoles extend at an angle partway across the entrance, parallel to the bank's terminal on the south side of the entrance and perhaps indicating the line of a structure designed to channel movement into the south part of the interior or to screen the northern part from the eyes of those entering. Another large dipole appears at the northern edge of the plot (Illus 5, A), in the interior. The dipoles visible in the interior and along the bank of the smaller enclosure may indicate that it contained pits or standing posts.

If these anomalies do indicate post holes, their nature suggests that the posts were either burnt or decayed in situ to produce the magnetic response recorded. The coherent nature of all of the dipolar responses suggests that the enhancement of magnetic properties took place in situ. This makes cremation deposits unlikely, as the deposition of the cremated remains would be likely to disrupt the dipolar nature of the response, producing a weaker magnetic signal (see Aitken 1961).

\subsubsection{Chester Hill}

The monument sits on the rounded summit of Chester Hill, at $300 \mathrm{~m}$ above OD. It is sub-circular in form, the circle slightly flattened on the north-east. Two turf-covered banks and a medial ditch define the monument, which measures $82 \mathrm{~m} \mathrm{NNE/SSW}$ by $86 \mathrm{~m}$ ESE/WSW internally. Illus 6 shows the survey plan 


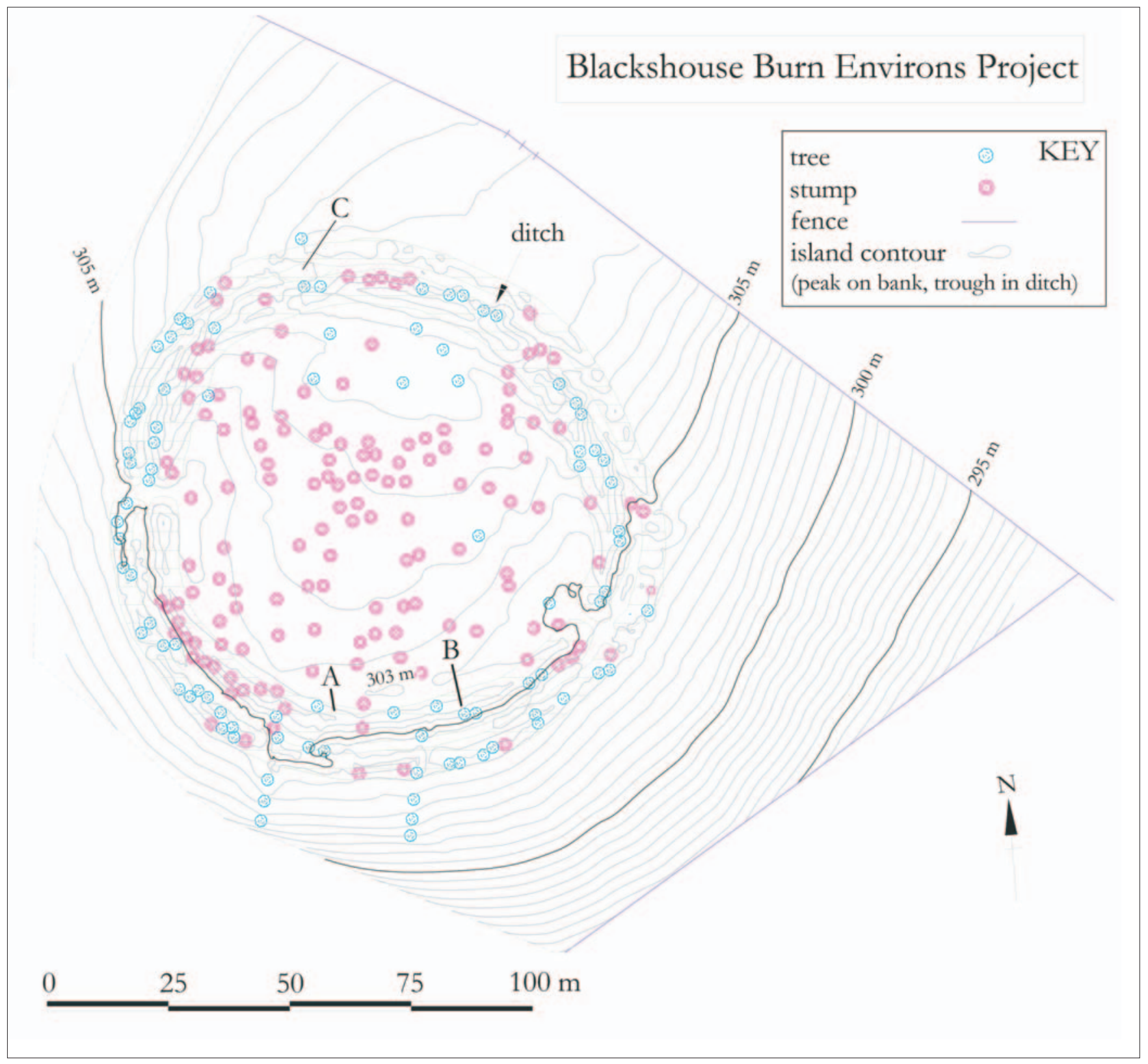

Illus 6 Survey plan of Chester Hill earthworks

of the monument and the locations of trees and stumps.

The inner bank measures on average $6 \mathrm{~m}$ wide and stands to $c 1.4 \mathrm{~m}$ above the interior and $2.3 \mathrm{~m}$ above the base of the ditch, while the outer rampart measures 4-5 m wide and stands to $c 1 \mathrm{~m}$ high at most; in places, particularly in the NNW sector, it stands to no more than $0.5 \mathrm{~m}$. Where cattle and sheep have eroded the banks, angular stones generally under $0.3 \mathrm{~m}$ across are visible in a light brown loamy soil matrix. The banks are broken by two offset entrances, one on the ESE and the other on the west side. The terminals of the outer bank are slightly inturned to either side of both entrances. The western entrance looks down on the small valley that leads toward present-day Hyndford Bridge, site of a former ford and perhaps a longstanding crossing point on the River Clyde. The other entrance looks up the Clyde Valley toward the river and the fort of Quothquan Law.

In the 19th century, the monument was incorporated into the designed landscape of the Carmichael estate, with deciduous and coniferous trees planted on the banks and in the interior, and an avenue of beeches planted on the hill slope leading up to the monument from the south. Most of the trees in the interior have now been cut down, although many still stand on the perimeter banks and in the intermediate ditch. Their root systems have almost certainly disturbed the fabric of the banks and any archaeological features surviving inside the monument. A portion of the outer bank on the NNW (marked C on Illus 6) is nearly flattened, presumably by ploughing or stock encroachment in the past. 


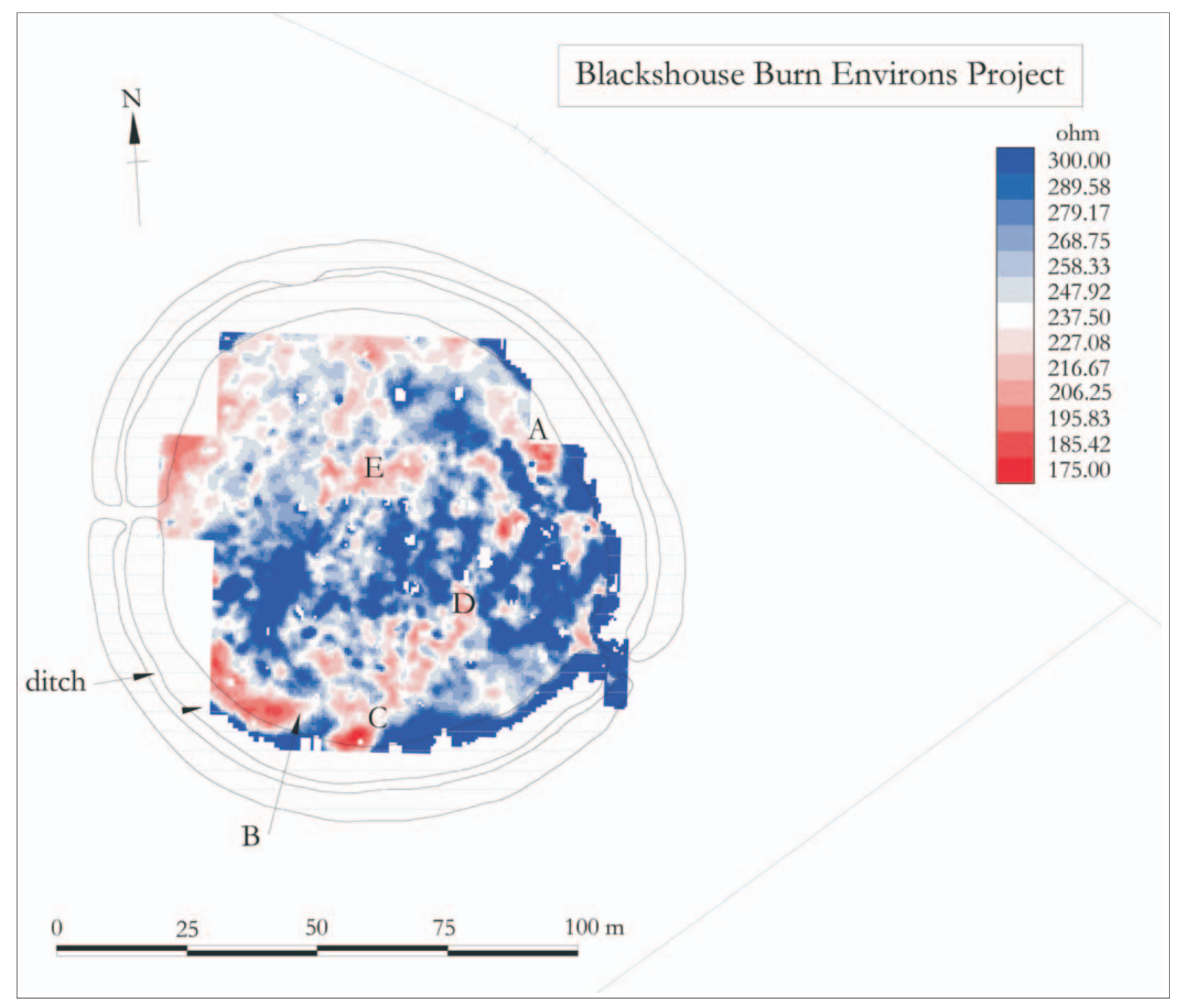

Illus 7 Chester Hill resistivity plot

Inside the enclosure a slight hollow is visible concentric with the inner bank; it measures an average of $1 \mathrm{~m}$ wide. This may be the result of contiguous quarry scoops, produced by quarrying material to build the banks, as suggested previously (RCAHMS 1978, 97, no 224) and illustrated by geophysical survey of the monument (see Illus 7 and Illus 8). The hollow creates a slightly raised platform which dominates Chester Hill's interior.

Geological maps for this area indicate that the Chester Hill monument overlies a solid geology of upper Silurian (Downtonian) sandstones. However, there are a large number of blocks of quartz conglomerate visible at the surface on the banks and the interior. This rock is mapped as a band trending north-east/south-west around three-quarters of a mile north-west of the enclosure (British Geological Survey 1:63,360 map, Sheet 23, Solid). From the surface evidence, it is difficult to say whether the visible blocks represent a previously unmapped occurrence of this rock type or whether it is instead evidence of glacial erratics. It may even be that the builders of the monument used the rock in its construction. The local geology and soils provided a reasonably quiet, consistent background for detecting features. The survey results do not indicate excessive interference from high magnetic materials at the fort.

The resistivity survey (Illus 7) indicates the position of curvilinear anomalies concentric with the inner bank. The Royal Commission surveyors had described this as a series of quarry scoops (RCAHMS 1978, 97, no 224). The variable resistance met around this feature could mark a series of scoops; alternatively, the values recorded could indicate an internal ditch and may be used to pose questions regarding the entrances to the enclosure.

The resistivity survey calls into question the assumption that the entrances in the west and ESE are original. The ESE entrance gave a very high 


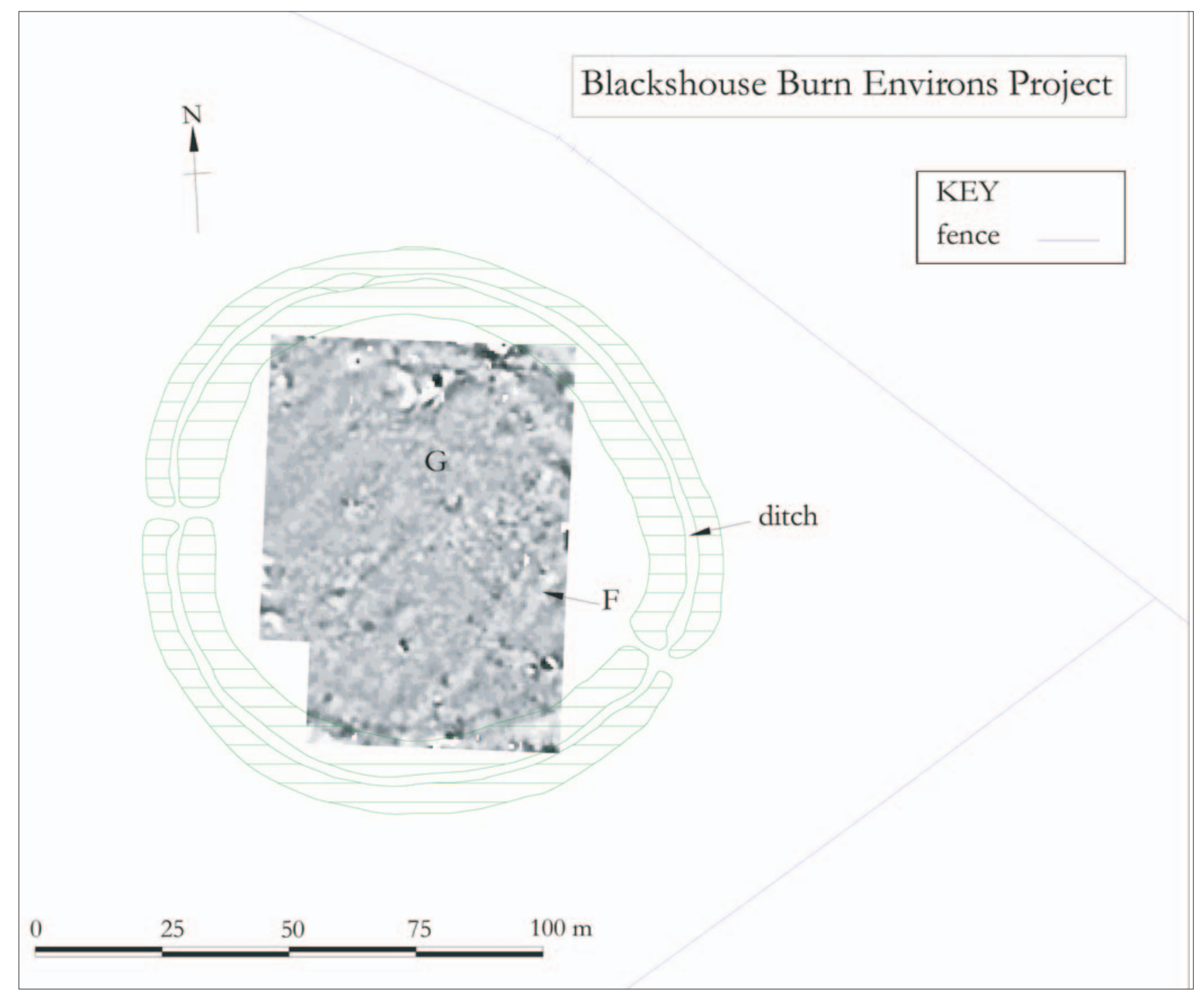

Illus 8 Chester Hill gradiometer plot

resistance signal. There is a large amount of stone rubble visible at the surface in this entrance, and a widening of the banks at this terminal point. The high resistance in this entrance is most likely to be due to the partial collapse of the stone-built banks over time. It is also possible that the entranceway was metalled, perhaps with cobbling.

The western entrance, by contrast, showed no sign of high resistance features. In fact, the resistance values in front of this entrance suggest that the internal ditch or series of quarry scoops continues across it. This could suggest that the western entrance is not an original one. However, this interpretation is offered with caution, as this part of the enclosure was surveyed in December 1998 after a period of sustained wet weather, which will have slightly affected the resistance values recorded.

There is a possible third entrance to the monument, in the southern arc. This arc adjoins the avenue of trees which leads up to the monument from the south-west, and for years visitors may have entered the enclosure from this side. This will have caused the ground to become compacted locally and might give the appearance of a third entrance. However, the resistance values do indicate that the internal ditch or series of quarry scoops is interrupted at this point (see Illus 7, B), revealing a possible rounded terminal. An adjacent area of high resistance, $c 7 \mathrm{~m}$ wide, lies east of the terminal and could be interpreted as an entranceway into the interior.

This leads to the second area of interest on the resistance plot, inside the south-eastern entrance. There are no obvious indications of the internal ditch between point $\mathrm{B}$ and the south-eastern entrance. The only low resistance feature detected here is the linear one ( $\mathrm{C}$ to $\mathrm{D}$ on Illus 7 ) trending north-east/ south-west in the southern part of the enclosure. This feature is also clearly visible on the magnetic survey plot (Illus 8, F). It may represent a ditch relating to an internal structure.

The central part of the enclosure rises from the 


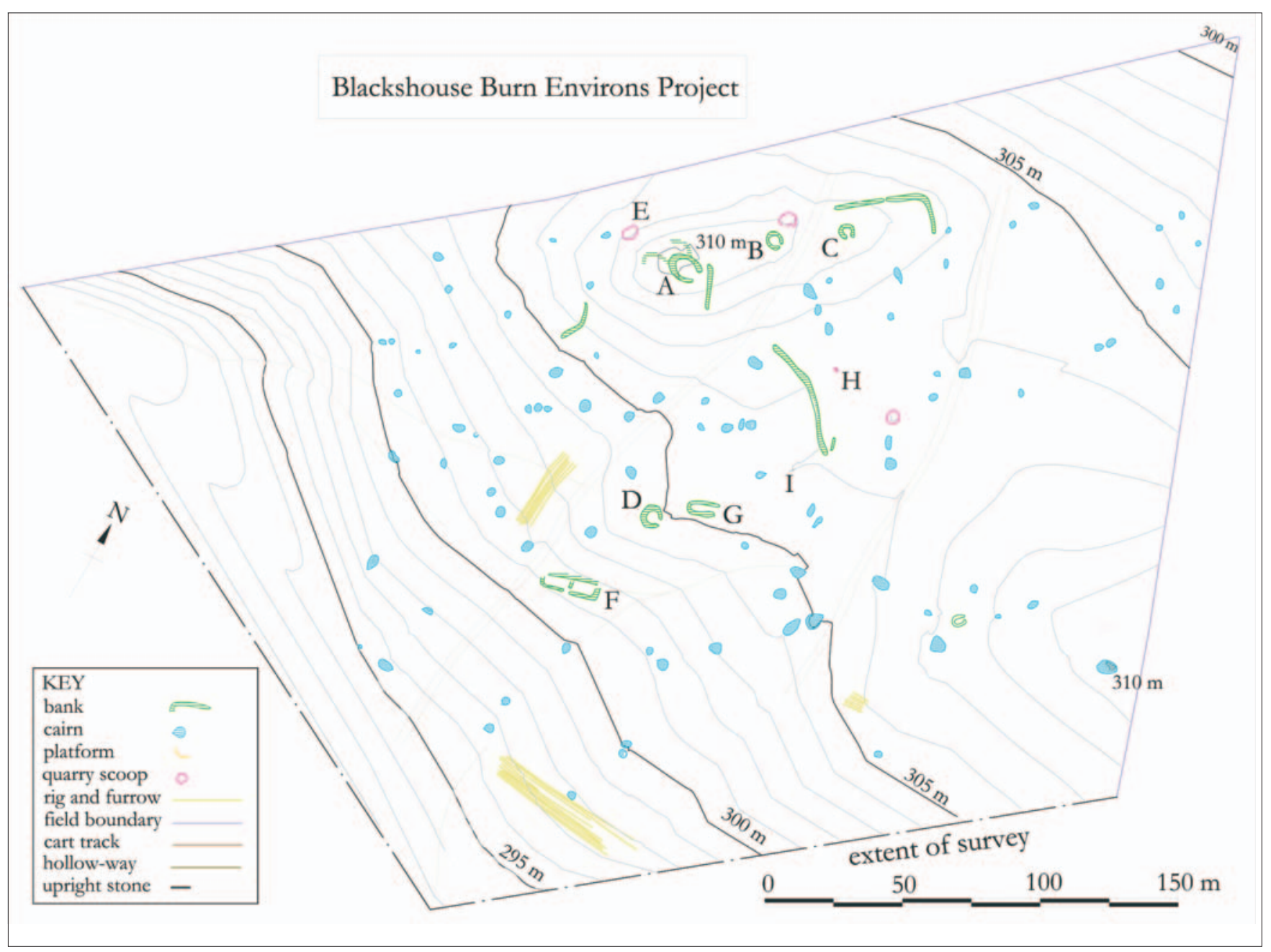

Illus 9 Survey plan of Cairngryffe Hill

internal ditch or series of quarry scoops to a slightly domed, south-facing area, its edge defined by positive anomalies on both survey plots.

There is a second possible structure, marked E on Illus 7, which is also faintly visible as a magnetically disturbed area on the gradiometer plot (Illus 8, G). Otherwise, the changes in resistance over the interior are probably due to the trees and tree stumps and to small, local variations in topography resulting in differential soil moisture levels.

The gradiometer survey (Illus 8) again defined the possible internal ditch. It appears as a slightly negative anomaly, as would be expected, and the edges appear as a positive anomaly with an associated, very subtle negative rim.

In addition to anomalies $\mathrm{F}$ and $\mathrm{G}$ on Illus 8, discussed above, several dipolar anomalies are visible in the plot (Illus 8). If tree planting or metal fence debris can be eliminated as the source, then the cause of these anomalies may be attributable to activities relating to burning, for example in-situ burning of posts. Another possible cause is more highly magnetic bedrock coming closer to the ground surface at the base of quarry pits. There are a number of other dipole anomalies scattered across the interior of the enclosure. Every trace of metal contamination observed was removed prior to the survey commencing, and every extreme reading was investigated in an attempt to eliminate surface metal as the cause. Even so, at least some of these dipoles could have been caused by metal spikes. Others, however, may indicate the presence of hearths or other burning events.

\subsubsection{Cairngryffe Hill}

To the south and south-west of Cloburn Quarry, at the north-west end of the Pettinain Uplands, is a well-preserved fragment of prehistoric landscape. The archaeological remains comprise structures, field banks, clearance cairns, cultivation traces, trackways and hollow-ways, with some of the elements relating to more recent agricultural use (see Illus 9).

The monuments lie on an open, south-west-facing slope of Cairngryffe Hill, immediately south-east of the quarry road and, at the time of survey, southwest of an area containing heaps of rose, pink and lilac felsite gravel. The grassy ground of the survey area appears never to have been improved or colonized by heather, which must account for the 
monuments' visibility and relatively good preservation. The trapezoidal field in which they lie rises to two low knolls (both at $310 \mathrm{~m}$ above OD) at its northern and eastern edges and descends southwestward $18 \mathrm{~m}$ into a boggy gully cut by modern drainage ditches.

The earliest occupation is most likely represented by several sub-circular structures (interpreted here as small hut circles) and associated clearance cairns and field banks. The structures are all defined by slight, turf-covered banks standing no more than $0.3 \mathrm{~m}$ high, with entrances on the south-east. The largest of these (Illus 9, A) sits atop the highest point on the western of the two knolls. Oval in plan, it measures $9 \mathrm{~m}$ south-east/north-west by $6 \mathrm{~m}$ internally. Two curving lengths of much more ephemeral bank extend from it to the west, creating a subtle platform on that side.

Another smaller sub-circular structure (Illus 9, B), measuring $c 4 \mathrm{~m}$ in diameter internally, sits on the lower end of the knoll's summit, $25 \mathrm{~m}$ to the north-east. A third (Illus 9, C) of similar dimensions lies another $20 \mathrm{~m}$ to the north-east on still lower ground. The remains of another structure (Illus 9, D) of similar form, measuring $4 \mathrm{~m}$ in diameter internally, lie approximately $80 \mathrm{~m}$ to the south of the larger hut circle. A platform (Illus 9, E) measuring $c 8 \mathrm{~m}$ across is levelled into the west-facing slope of the western knoll, although there are no signs of a structure on it. This group of features clustered around the western knoll appears to represent a prehistoric settlement associated with the numerous clearance cairns and field banks around them.

Approximately 90 small cairns are scattered over the hill slope, concentrated mostly between the $295-\mathrm{m}$ and 305-m contours. Several form rough alignments (at least six are apparent on the survey plot), running both down and parallel to the slope, perhaps indicating the edges of fields. The cairns measure from 1 to $8 \mathrm{~m}$ across; few are more than $1 \mathrm{~m}$ high. All are turf-covered, with stone apparent in their fabrics.

Several lengths of slight, turf-covered bank lie among the cairns on the east, south-east and south sides of the western knoll, radiating from the top of the knoll and the structures on it. Some patches of narrow rig (c $0.8 \mathrm{~m}$ wide) lie among the cairns, running across and down the slope.

While the hut circles, field banks and small cairns appear to represent a coherent, mutually referencing group of prehistoric settlement remains, perhaps contemporary with the later, Bronze Age phases of the ring cairn excavated on the summit of Cairngryffe Hill (Lelong \& Pollard 1998b), their dating is not certain. At Burnhouse Moor, to the south-west of Tinto Hill in Clydesdale, a sub-circular structure overlying cultivation rigs of unspecified width was interpreted as a possible shieling hut or sheep pen (Ross 1999).

A structure (F on Illus 9) of distinctively different form lies lower down the slope and parallel to it, at $301 \mathrm{~m}$ OD. It is sub-rectangular and appears dug into the slope, defined on the south by slight, turf-covered banks. It measures $18 \mathrm{~m}$ east/west by $4 \mathrm{~m}$ internally, and is divided in half by an internal partition, with two entrances in the south-east. Little stone is evident in the banks, and they may have been largely of turf construction. It may be a shieling hut (albeit a large example), associated with a sheep-milking bucht about $45^{\circ}$ to the north. This is a U-shaped structure ( $\mathrm{G}$ on Illus 9) that measures about $10 \mathrm{~m}$ east/west by $2.2 \mathrm{~m}$ internally, probably a bucht or open-ended pen into which ewes were driven for milking. Juxtapositions of such structures are fairly common 17th- to 18th-century sheep management features in the region, usually found above the head dyke, such as those at Dyke Farm, Biggar (Ward \& Brown 2001) and Glenochar (Ward 1998). The larger structure may also be comparable to some of the later buildings excavated at Fall Kneesend, near Elvanfoot in the Upper Clyde Valley, which were interpreted as possible shieling huts (Downes 2001).

A hollow-way leads downslope toward the shieling hut from a cart track to the east, while another cart track skims the building on the west. Both tracks could well be contemporary with the hut and bucht. Two other hollow-ways run from the area of the structures toward the south-west.

Several sub-circular hollows, filled with water at the time of survey, are dotted around the survey area. Some of these have been interpreted as quarry scoops and are shown as such on the plan, while others are likely to be natural features. One, in the northeastern part of the plan, is bordered on the east by what appears to be a wedge-split stone (Illus 9, H).

Near the centre of the survey area, at $306 \mathrm{~m} \mathrm{OD}$, is a triangular monolith (Illus 9, I). It stands over $1 \mathrm{~m}$ high, and is visible from much of the hill slope. It stands among clearance cairns and near a length of field bank. Although no other features seem to refer to it, its prominence and distinctive shape could have made it a focal point of some kind for those living in the vicinity.

\subsubsection{Swaites Hill}

Another group of archaeological remains of probable prehistoric date was surveyed on the summit and the north- and north-west-facing slopes of Swaites Hill, at the northern end of the Pettinain Uplands. This consists of small cairns, platforms, cultivation traces, hollow-ways and what may be a ring cairn (see Illus 10).

The monuments lie at between 291 and $322 \mathrm{~m}$ OD. Most of the features are under thick heather, although rough grass covers the summit of the hill and parts of the north-facing slope. The area surveyed measures a maximum of 940 m north-east/ south-west by $530 \mathrm{~m}$. An unmetalled road serving Cloburn Quarry runs along the north-west edge of the survey area at the base of the slope; the area to the west, bordered by a fence, was at the time of survey covered with heaps of quarried felsite. 


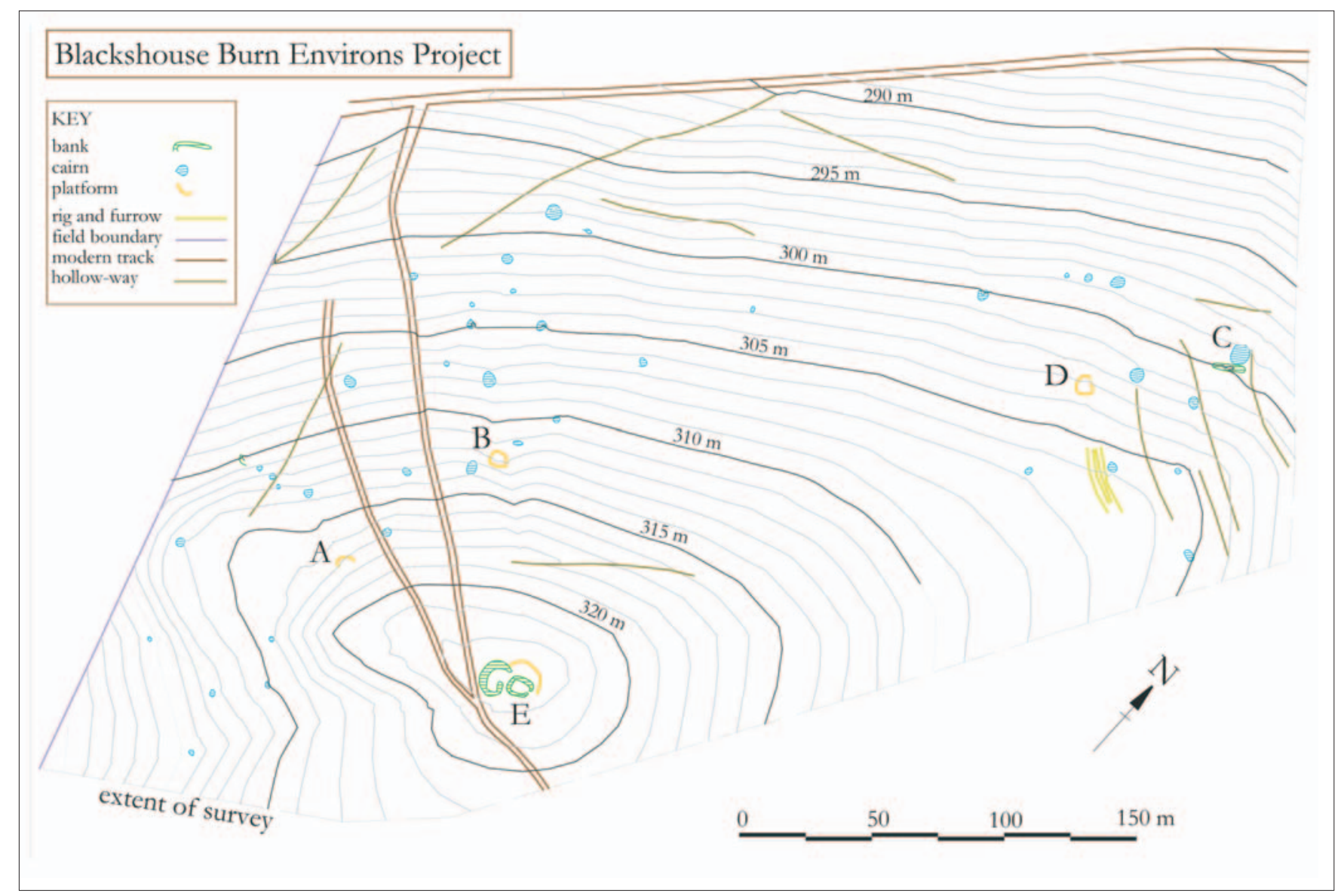

Illus 10 Survey plan of Swaites Hill

The survey recorded approximately 40 small cairns, all at between 298 and $317 \mathrm{~m}$ above OD. Most measure between 1.5 and $10 \mathrm{~m}$ across, and stand up to $1 \mathrm{~m}$ high. The cairns in the western part of the survey area form a distinct group, with a clearly delineated upper edge running diagonally across the slope. Some of the cairns in this group form rough alignments that may indicate the edges of former fields. Two platforms (Illus 10, A and B), measuring up to $12 \mathrm{~m}$ across, are terraced into the slope at the top of the cairn field. The spatial coherence of this group of features suggests they comprise a small Bronze Age unenclosed platform settlement, such as that excavated at Lintshie Gutter in Crawford, Lanarkshire (Terry 1995).

Another group of cairns was recorded on the lower part of a north-facing spur on the eastern side of the survey area. This smaller group includes one larger cairn (Illus 10, C), measuring $14 \mathrm{~m}$ across, with an associated bank along its south-east side. Another platform (Illus 10, D), measuring $12 \mathrm{~m}$ across, is terraced into the slope near the top of the cairn field. There are traces of rig and furrow cultivation, with rigs up to $4 \mathrm{~m}$ wide, among the cairns.

Several hollow-ways run among the cairns, parallel to the rig and furrow. Other lengths of hollow-way run along the slopes of the survey area. The positions of these larger cairns relative to the hollow-ways could suggest they are the result of relatively recent field clearance.

At the summit of the hill a modern farm track skims the edge of a large, complex feature (Illus 10, E), previously identified as a cairn by the Royal Commission (RCAHMS 1978, 65, no 106[7]). It comprises two sub-circular, turf-covered banks, one immediately east of the other, enclosing areas of up to $18 \mathrm{~m}$ and $12 \mathrm{~m}$ across, respectively. The banks measure up to $6 \mathrm{~m}$ wide and appear spread and somewhat disturbed (in one place by fairly recent vehicle traffic diverging from the farm track). Curving around them to the north and east is a much slighter bank or scarp defining an associated platform.

Although these features could be structures, several factors make it more likely that they represent a ring cairn or cairns. They occupy a very exposed position on the summit of the hill, well above the clearance cairns and platforms on the slopes below. From this position, one can see across to the large cairn on Tinto Hill, the Hero's Cairn at Meadowflatts, the sub-circular enclosure on Chester Hill and, in the distance, the massive cairn on Cairnpapple in West Lothian.

Before its destruction by quarrying, one would also have been able to look directly westward to the excavated ring cairn on Cairngryffe Hill. 
This feature was recorded in the 1985 survey as a possible house platform when it appeared as a sub-circular structure defined by a slight bank. As discussed in the archaeological background for the project (Section 3.2), excavation proved that this was a Bronze Age ring cairn, built over early Neolithic ceremonial remains and containing early Bronze Age cremations (Lelong \& Pollard 1998b).

The monument on the summit of Swaites Hill is similar in form to the Cairngryffe ring cairn's appearance before excavation. It has a similarly elevated position, which is too exposed to have been suitable for domestic habitation and seems deliberately chosen for its visual links with ritual structures on the surrounding hilltops. The two sub-circular banks comprising the possible Swaites Hill ring cairn could indicate multiple phases or structural complexity.

\subsection{The lower slopes and valleys: field walking and trial excavation by $M$ Donnelly and $O$ Lelong}

\subsubsection{The results of field walking by $M$ Donnelly, with comment on the pitchstone by T Ballin}

The 15 ploughed fields examined on the lower western and south-western slopes of the Pettinain Uplands and in the valleys to the west (see Illus 1, AR) varied considerably in their lithic content. Fields $\mathrm{D}$ and $\mathrm{M}$ produced significant quantities of lithic material numbering in the hundreds. Field K produced close to 100 pieces of lithic material. Fields A/B, G, H and L produced small assemblages, while Fields $\mathrm{C}, \mathrm{J}$ and $\mathrm{N}$ produced a few finds and Fields $\mathrm{E}$ and $\mathrm{F}$ produced no material of note.

Fields A/B, which lay closest to the Blackshouse Burn enclosures and were subjected to a second, intensive examination over a selected portion, produced a small assemblage of 24 lithics as well as a lump of glass and a five penny silver coin dating to the reign of George III.

Chert (20 pieces) is the dominant raw material, with small quantities of quartzite (two pieces) and solitary examples of flint and chalcedony. The assemblage is very small and displays a mix of blade (three pieces) and flake (14 pieces) forms. Waste (five pieces) is rare and there is a single, bipolar chert core. There is a single formal tool type, a partially worked discoidal knife of chert. Such objects are usually dated to the late Neolithic to early Bronze Age. Two flakes, one of chert and the chalcedony examples, display faceted platforms which are also indicative of the late Neolithic. The lithics recovered from these fields appear broadly contemporary with the late Neolithic activity at the nearby monuments.

Field C, on the lower western flank of Chester Hill, produced two chert flakes and a single sherd of medieval, green-glazed pottery.
Field D (in reality two fields divided by the Blackshouse Burn), in the valley to the west of the monuments, produced significant quantities of lithic material during its initial sweep and was then examined more intensively. This produced a large number of lithics dispersed throughout the field in several clusters. These were not particularly discrete and none appeared suitable for trial excavation. The field produced 131 artefacts, including six pieces of medieval and post-medieval pottery, two pieces of clay pipe and a fragment of industrial waste. A solitary hammerstone and a possible axe-sharpening flake were also recovered. A variety of raw materials are present within the assemblage. Chert (106 pieces) dominates, followed by flint (eight pieces), quartz (three pieces), agate (one piece) and pitchstone (one piece). The assemblage of 119 lithics consists of flakes (69 pieces), waste (29 pieces), tools (14 pieces) and cores (eight pieces); one of the tools is classified as a core/tool, so the assemblage appears to contain 120 instead of 119 pieces.

The pitchstone piece is a very small platform flake or chip $(8 \times 6 \times 1 \mathrm{~mm})$, in homogenous dark green/black pitchstone with good flaking properties. The raw material is most likely to be the Corriegills variety, that is, the best of the four recognized varieties of Arran pitchstone (Williams Thorpe \& Thorpe 1984, 3-5).

The assemblage contains a full range of decortical, preparatory, trimming, rejuvenation, regular and irregular flakes, suggesting that the reduction of nodules to cores and the production and use of blanks and tools all took place within the field. A lack of blade forms suggests that the bulk of the assemblage is late and the rarity of faceted platforms may support a date range in the earlier part of the Bronze Age. Beyond the formal tool types retouch is rare, occurring on only four of the 69 flakes, and indicating that the vast majority of the flakes are waste from tool production.

The cores are predominantly tabular, bipolar cores geared to the production of flakes (Illus 11, D10). These tended to be found in the northern half of the field, where the densest lithic concentrations occurred. A single blade core was also recovered, this at the southern end of the field. The tools from Field D include a number of typically late scraper types such as the well-fashioned side (Illus 11, D114) and double side scrapers (Illus 11, D124) on small regular flakes, as well as some that could be considered as earlier in date. Also discovered was a non-geometric microlith (a large, irregular scalene triangle; Illus 11, D201) that may date to the early Mesolithic. In addition to this there were two awl-scraper composite tools, a denticulate and a burin, that may also date to this period.

The early Mesolithic material appeared scattered throughout the field, but the later prehistoric tools were concentrated in the southern central part, away from the distribution of cores. It is therefore possible to identify a zone of tool or blank production in the northern half of the field and an area of tool use 


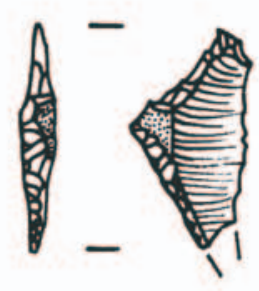

D201

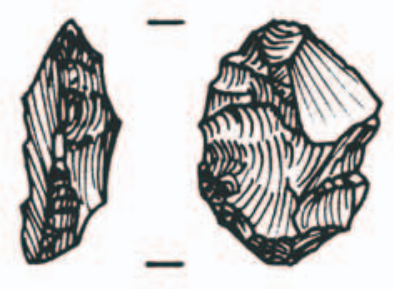

Area D

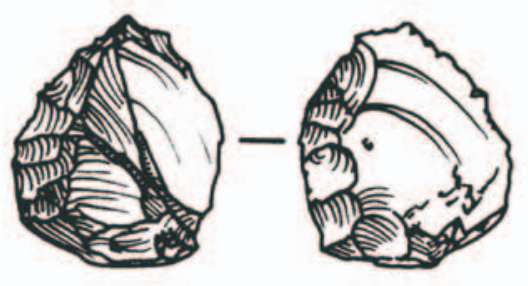

D124

D114

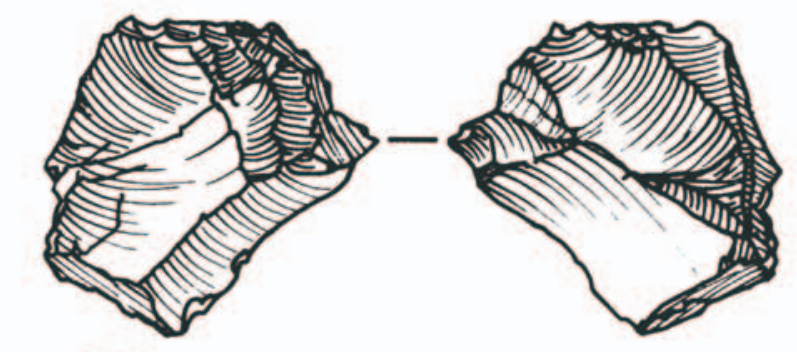

D10
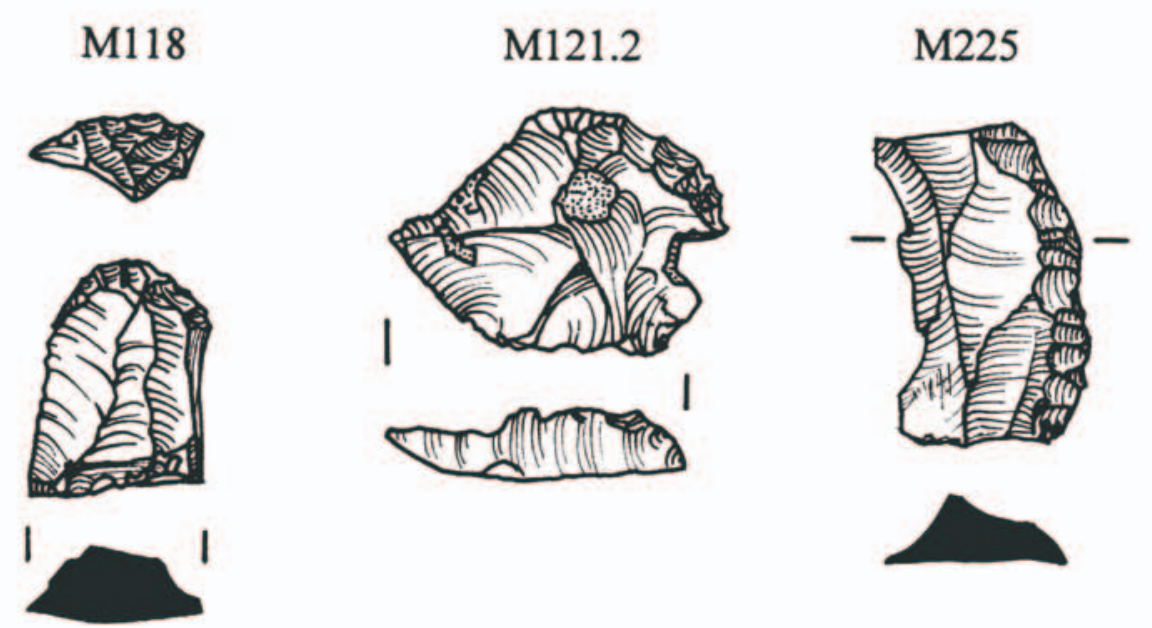

M517 M547 M612
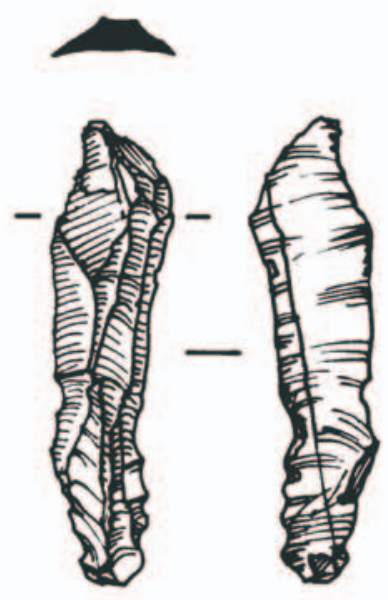

M480.2
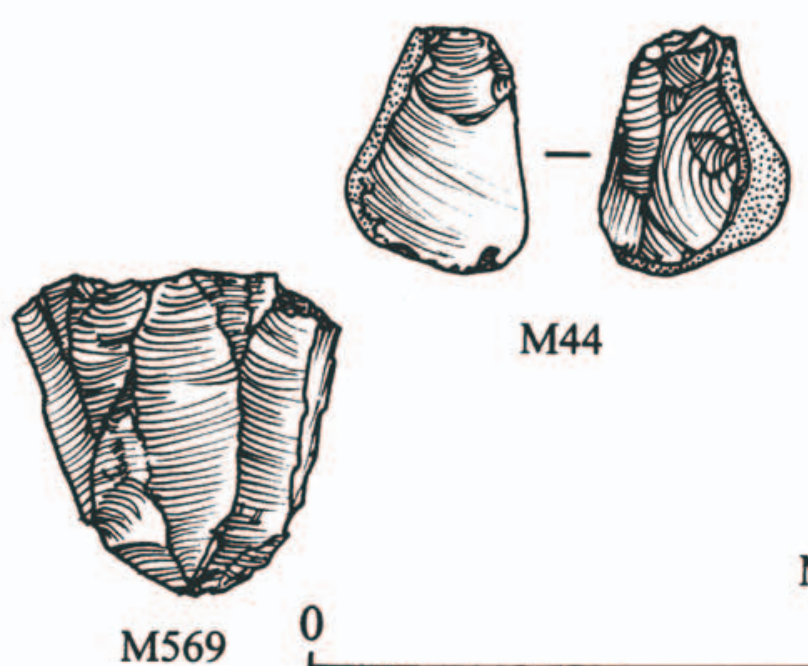

Area $M$

Illus 11 Lithics from Fields $D$ and $M$ on the Carmichael estate 
and/or discard in the southern half of the field. These zones relate to late Neolithic to Bronze Age activity, while scattered throughout the field was a small but significant amount of early Mesolithic material. However, the pitchstone chip does suggest possible early Neolithic residuality on the site.

Pitchstone was mainly exchanged in the early Neolithic, with some possible limited exchange during the late Neolithic and early Bronze Age; on the Isle of Arran it was also used in the Mesolithic (Ness \& Ward 2001). The pitchstone flake from Field $\mathrm{D}$, although tiny and not particularly diagnostic in itself, does indicate some form of contact or exchange with the Isle of Arran, most likely in the early Neolithic.

Fields E and F, immediately south-east of Field D in the same valley, produced very little material during their initial sweeps. No further work was conducted in these fields.

Field G, on the south-east flank of Chester Hill, was walked during the initial sweep and produced a surprising quantity of lithic material, considering its steep slope. The assemblage of 13 items includes both chert (nine pieces) and flint (four pieces). Cores are absent, as are blades. Flakes (seven pieces) dominate, along with waste (three pieces) and tools (three pieces).

The main objects of note are the three tools, which consist of two side scrapers of flint and a chert awl. These tools would sit easily within a late Neolithic to early Bronze Age context, although the possibility that the material is later still or from a variety of periods must also be considered. This field (along with Field H) sits directly below Chester Hill enclosure which, although generally assumed to be Iron Age in date, could conceivably be earlier or overlie earlier prehistoric remains (see Section 6.2).

Field $\mathbf{H}$ lies immediately to the north-east of Field $\mathrm{G}$ and is similarly steep. Despite this, the field produced 22 archaeological artefacts, including a pot handle of fairly recent date and a sherd of medieval to post-medieval pottery, all recovered during the initial sweep.

The lithic assemblage contains 14 pieces of chert and four pieces of flint. Flakes (10 pieces), blades (two pieces), cores (three pieces), tools (one piece) and waste (four pieces) are all present. The cores are generally later prehistoric, consisting of a tabular multi-platformed flake core (chert) and two tabular bipolar flake cores (one of flint and one of chert). The solitary tool is a flint side scraper. Both blades are of chert and are retouched, one with 'knife-like' invasive retouch. The flakes represent a mixture of preparatory, regular and irregular examples, one of which has been retouched while another displays a faceted platform.

A similar date can be suggested for the material from Field $\mathrm{H}$ as was indicated for Field G, although here the likelihood of mixing within the assemblage is higher. It is possible that the material from Fields $\mathrm{G}$ and $\mathrm{H}$ has moved down the steep slope and may represent disturbance of a site or several sites at the top of Chester Hill, currently occupied by the enclosure.

Field $\mathbf{J}$, in the valley of the Glade Burn to the south of Chester Hill, produced very little material during its initial sweep, despite its size and proximity to the more productive Field K. No further work was conducted in this field.

Field K, which extends along the valley floor south-west of Field J, produced 64 artefacts, including a sherd of post-medieval pottery and a piece of industrial waste. After its initial assessment, this scatter was walked using the more intensive methodology.

The 62 lithics recovered included chert (49 pieces), flint (six pieces), agate (four pieces), quartz/quartzite (two pieces) and stone (one piece). Flakes (40 pieces) dominate the assemblage, followed by waste (13 pieces), cores (six pieces), blades (two pieces) and a single tool, a very crude side scraper. The cores were used solely for the production of flakes from tabular cores, with a variety of platform complexities evident (single, opposed, bidirectional and multi-platformed). Two of the cores are bipolar.

Two of the 40 flakes display faceted platforms typical of the late Neolithic. This type of removal strategy often gives way to a bipolar strategy as the cores become progressively smaller. Such a dual strategy was observed among pieces from a single pit at Fox Plantation dated to the late Neolithic (MacGregor forthcoming). Retouch is rare within the assemblage and it is likely that the material from Field K relates to tool or blank production as opposed to tool use. This has probably taken place during the late Neolithic.

Field L, to the south of Carmichael village, produced very little material during its initial sweep. This field covers a north-west-facing slope, with one or two flat terraces suitable for habitation. Despite its proximity to the very productive Field M, because of the small quantity and inferior quality of the lithics recovered, no further work was conducted here.

Field M, immediately south of Carmichael village, produced the largest quantity of lithic material and also the most obvious concentration of lithics; it was walked intensively following its initial sweep. A dense scatter in the north-west corner of the field was chosen for trial excavation, leading to the recovery of over 600 lithics (Section 5.2.2). Although a total of 662 objects were collected during field walking and trial trenching, 199 were rejected as entirely unworked objects, producing a total of 463 genuine artefacts. The lithics recovered during the trial trenching are discussed below, along with those identified on the surface of the scatter.

The field produced 244 flakes, 87 pieces of waste (mostly angular shatter), 40 blades, 37 cores, seven microliths and 17 other tools; 31 other objects recovered included a sherd of Beaker pottery and one of Food Vessel, a probable cannel-coal bracelet fragment, medieval and post-medieval pottery and glass. The tool types (10) and cores (14) from outside 
the main concentration appear to represent a mixture of early and late forms, with some typical conical and cylindrical blade cores found side by side with amorphous flake cores and flake-producing bipolar cores. Tools such as large, complex scrapers, thumbnail scrapers and knives (Illus 11, M255) were also present.

The main concentration in the field's north-west corner (see Illus 12) produced 312 of the 463 artefacts, including 34 of the 40 blades, all seven of the microliths, seven of the 17 other tool types and 23 of the 37 cores. This concentration also produced 173 of the 244 flakes, 58 of the 87 pieces of waste and 10 of the 31 other objects, including (rather surprisingly) the sherds of late Neolithic Impressed Ware and Beaker. The close proximity of these sherds to microliths, narrow blades and bladelet cores suggests that they are intrusive to the main concentration.

The 23 cores consist of 14 uniplane, two penannular and seven biplane examples. Single platforms account for 15 of the 23 examples, with four bidirectional, one opposed and three multiplatformed variants. Tabular cores (10 pieces) dominate, followed by cylindrical (six pieces), semiconical (three pieces) and conical (three pieces) and, finally, amorphous (one piece). There are 10 flake-producing cores, of which four are rough test cores abandoned after the removal of only a few flakes, six blade and bladelet cores and seven cores on which both blade and flake removals can be observed. Bipolar technology is apparent in only one example and this is of flint, which suggests an attempt was made by the knappers to maximize the potential of this material, which is exotic to the area.

The seven tools recovered from the scatter consist of two end scraper-burin combinations (one definite and one possible; Illus 11, M121.2), a single end scraper (Illus 11, M118), three side scrapers and a side and end scraper. The blades are fairly narrow but quite long, indicating the good knapping quality that can be found in chert, and often display signs of retouch or utilization (Illus 11, M480.2).

The microliths display a wide range of typical narrow blade, geometric forms. There is a single scalene triangle (Illus 11, M517), a partial doublebacked bladelet or point (Illus 11, M547), a backed bladelet, a needle point, an unclassified example closely related to the lamelles-à-cran (Zetterlund \& McCartan 1990) and two fragments. Such a collection is typical of the late Mesolithic in certain areas of mainland Scotland, such as at Starr and Smittons in the vicinity of Loch Doon (Finlayson 1990), at Garvald Burn, Lanarkshire (Donnelly 1998; Barrowman 2000b, 313; Barrowman forthcoming) and at Littlehill Bridge, Ayrshire (MacGregor \& Donnelly 2001). Further excavation would be required in order to recover a large enough sample for detailed typological comparison.

Clearly the cores, blades, tools and microliths demonstrate that the main concentration in Field $M$ relates to late Mesolithic activity which could have taken place at any time between 7500 and 4000 BC.
The range of flakes, blades, cores, tools and waste indicates that knapping occurred on the site and that tools were probably generated as required and used in the immediate vicinity.

The site sits on a low knoll overlooking a broad, shallow depression, which may have held a small lochan or bog at the time. Furthermore, the site lies close to a burn. Given this position, it would have been a suitable base of operations for a small group of late Mesolithic people living off the varied ecosystems they would have found in the area (upland, valley, riverine and probably marsh/bog). This activity was followed by a phase of later prehistoric activity dating from the end of the Neolithic into the Bronze Age, the material from which appears as a diffuse background scatter intermixed with Mesolithic material. What this later prehistoric activity represents is still unclear, but the presence of later prehistoric cores as well as formal tools suggests that tool production occurred along with activities that led to tool abandonment, intentional or otherwise.

Field $\mathbf{N}$ is a small, relatively flat, triangular field at the base of Chester Hill (south of and across the road from Fields $\mathrm{G}$ and $\mathrm{H}$ ) and produced nine lithic items, all chert. These consisted of four flakes and five cores. The latter comprised two bladelet cores, two flake and blade cores and a single flake core. Three had single platforms, while two were bidirectional (two platforms at $90^{\circ}$ ). Conical, semi-conical, cylindrical and tabular forms were present. Such cores are often associated with early prehistoric assemblages and in particular the late Mesolithic, although they could also date to the early Neolithic.

Despite the proximity to Fields $\mathrm{G}$ and $\mathrm{H}$ and the incidental separation of these assemblages by the construction of the later road, this assemblage does not appear to relate to the same activity represented by the majority of the material from $\mathrm{G}$ and $\mathrm{H}$. Rather, it appears to relate to the possible mixing of the assemblage that was suggested above for Field $H$.

Field $\mathbf{P}$, to the west of Field M, produced extremely little material during its initial sweep. No further work was conducted in this field.

Fields $\mathbf{Q} / \mathbf{R}$, to the ESE of Chester Hill fort, produced extremely little material during their initial sweep. No further work was conducted in these fields.

\subsubsection{Trial excavation at Carmichael}

Four trenches were opened by machine over the lithic scatter in Field $\mathbf{M}$ (above) at Carmichael, after field walking and test-pitting had been carried out (see Methodology, Section 4.3.4); Illus 12 shows the trench positions. In each, the ploughsoil (001), a mid brown, fine, silty loam with abundant gravel, lay an average of $0.3 \mathrm{~m}$ deep above the sandy subsoil (004). Only Trenches 1 and 3 contained archaeological remains of any interest; these are described and discussed below. 


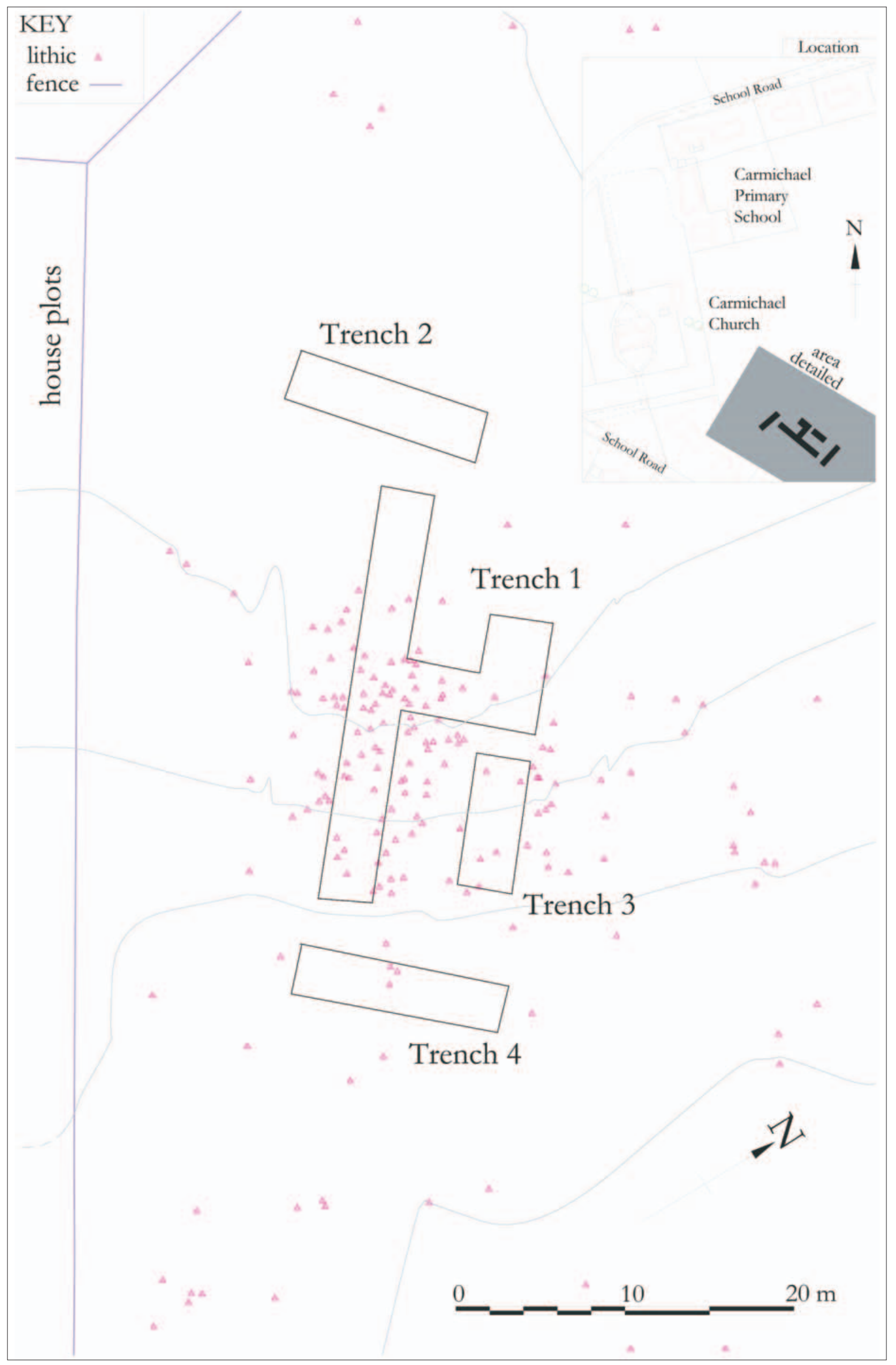

Illus 12 Location of trial trenches and lithic scatter at Carmichael 


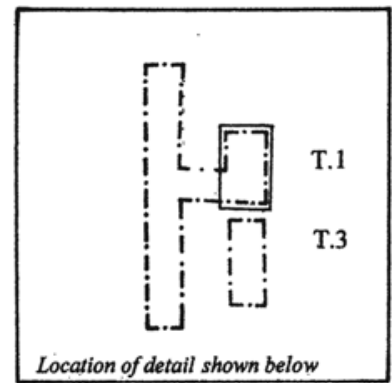

Trench 1 Plan

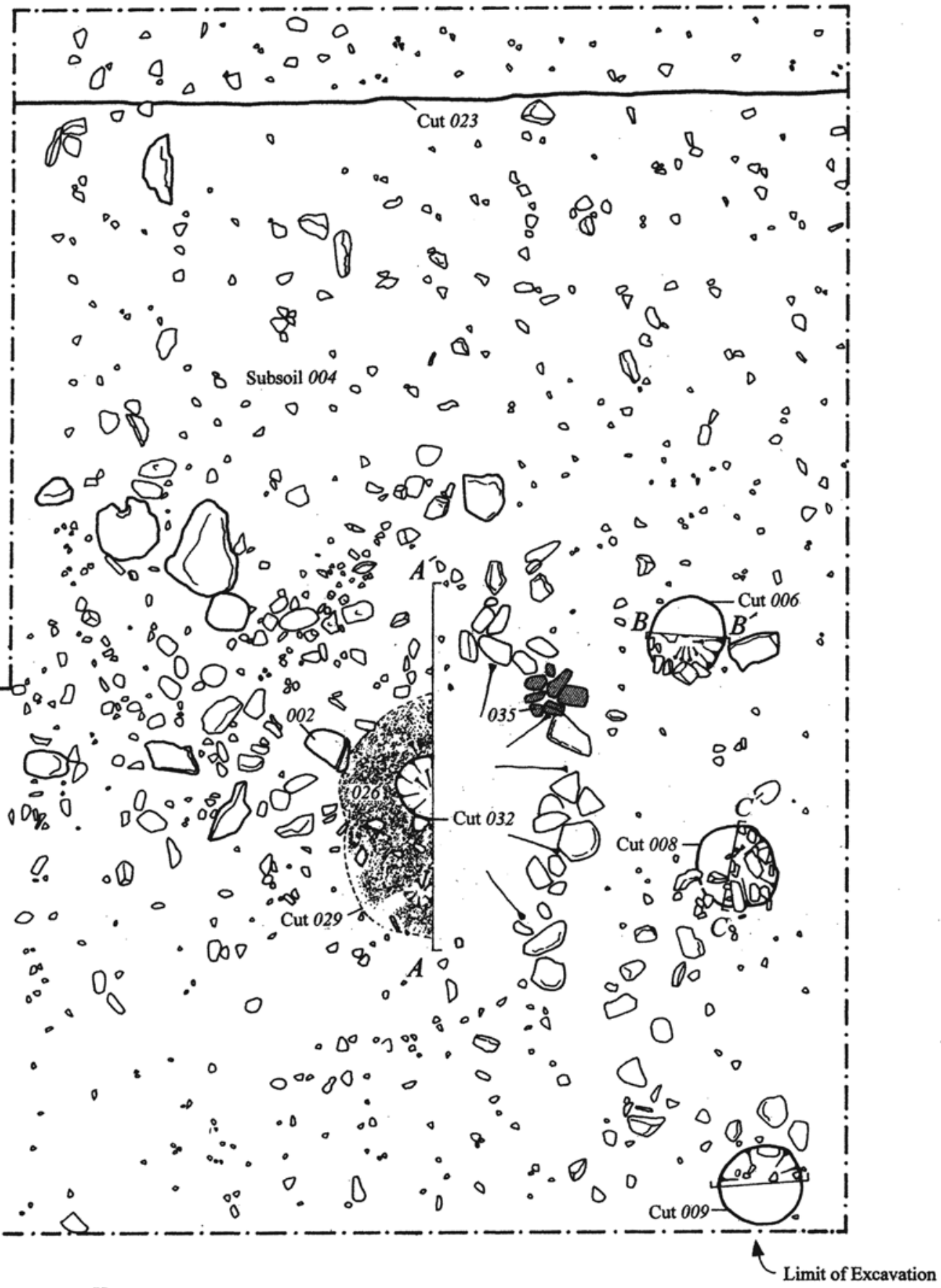

Key

图 charcoal possible posthole packing

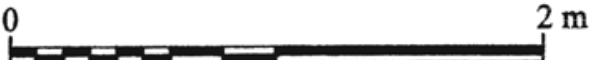

Illus 13 Plan of Trench 1 
The T-shaped Trench 1 was opened over the densest part of the lithic scatter, and extended north and east beyond its edges. After archaeological features and lithics were observed on the surface of the subsoil during machine excavation of the eastern leg of the trench, it was extended northward to establish the extent of these.

In the test pit (Illus 13, D) previously excavated by hand, at the junction of the two legs of the ' $\mathrm{T}$ ', a rim sherd of Impressed Ware in a coarse, gritty, thoroughly reduced fabric was recovered from the ploughsoil (sf M663). The vessel from which it came was large; its rim was $25 \mathrm{~mm}$ thick and had a slight internal bevel. Along the top of the rim and the exterior were rows of crescent-shaped impressions, made with a slightly irregular, pointed implement such as a twig or small bone. Late Neolithic Impressed Ware has been found at a number of other sites in Upper Clydesdale and Upper Tweeddale, including Biggar Common, and may be attributed to Burgess's 'Meldon Bridge style' (Burgess 1976; Speak \& Burgess 1999), which dates broadly to the 4th millennium BC (Sheridan 1997, 221).

Two concentrations of archaeological features were found in this trench. Cut into the subsoil at its western edge was an irregularly shaped, oval pit (028), with steep sides and a flat base (see inset, Illus 15). It was filled with a mixed dark grey-brown/light yellow-brown silt sand (027), extremely rich in lithics. Over 100 pieces were recovered from the fill, along with fragments of burnt bone and flecks of charcoal.

The edges of the pit were rather indefinite, and it may have been part of a larger feature or spread of dark red-brown silt sand (031) (not excavated), with abundant lithics in its surface, that extended westward from it to run into the trench edge.

Many of the lithics recovered from the pit (028) and from the surface of the spread (031) were pieces of knapping waste. This set of features was interpreted as the remains of a knapping floor of late Mesolithic date (see Section 5.2.1 above).

Another group of archaeological features lay c $9 \mathrm{~m}$ to the north-east of these, comprising a stony surface sealing a charcoal-filled hollow, and several post holes (see plan, Illus 13). The earliest feature identified was a spread of charcoal lumps in a black-brown silty matrix (026), which lay in a broad, shallow, oval scoop (029) in the subsoil. Although the base of the scoop did not appear scorched, the nature of the fill suggests that this was a hearth.

Above it lay a deposit of subangular cobbles (002) that covered a roughly rectangular area and also extended to the south-west of the charcoal-filled scoop. The bases of the lower stones were blackened, so they appeared to have been laid over the charcoal-rich material (026) soon after its deposition, perhaps to level or consolidate the ground. Most of the stones lay within a mid grey-brown sandy silt (003), interpreted as an old topsoil which subsequently developed around the stones (see section drawing, Illus 14, A-A'). A microlith was recovered from the old topsoil. This layer echoed the extent of the stones, and did not extend north or eastward as far as the post holes; it appeared to have survived ploughing only above the scoop itself.

Cut through the remnant topsoil (003) and charcoal-rich fill (026), near the centre of the scoop, was a roughly circular feature (032) (Illus 13; Illus 14, A$\mathrm{A}^{\prime}$ ). It was filled with what appeared to be redeposited sandy subsoil (033), with several upright stones packed together in its centre. This was interpreted as a post hole, post-dating the scoop and the formation of topsoil above it. At the north-west edge of the scoop, beyond the limit of the old topsoil spread (002), was a small stake hole (014) (see Illus 14, A-A'), apparently the remnants of a stake burnt in situ.

These two structural features may have been associated with several other post holes to the east, although ploughing had destroyed any stratigraphic relationship between them. About $1.3 \mathrm{~m}$ to the east and north-east of one post hole (032) were three sub-circular features that formed an alignment and were spaced at roughly a metre apart, all cut into the gravely, sandy subsoil (004). One feature (006) lay $0.6 \mathrm{~m}$ to the north of the post hole (032) and the other feature (008) $0.5 \mathrm{~m}$ to the north-east. The northernmost feature (006) had stones packed against its sides and base in a grey-brown clay sand (005); no post pipe was evident, but a slight ramp at the eastern side of the cut suggested a post had been pulled out (see Illus 14, B-B'). The middle feature (008) in the alignment was of identical dimensions to the nearby post hole (032) and had packing stones against its sides and base in a grey to yellow-brown sandy silt (007) and a possible post socket in the western part of the base (not illustrated).

The easternmost feature (009) in the alignment, while of similar size in plan to the other two, proved to be very shallow (about $0.10 \mathrm{~m}$ deep) and may have been a much more truncated post hole. Midway between one post hole (032) in the centre of the scoop and another post hole (006) was what may have been another post setting (035), comprising angular stones packed together and set upright in a shallow depression in the subsoil.

This group of post holes indicates the existence of a structure on the site; although the alignment of three possible post holes appeared to respect the hearth, if they were associated with the post hole (032) cut through its centre then the structure would have post-dated the hearth and the stones and remnant topsoil that sealed it. The recovery of a microlith from the remnant topsoil could suggest a date in the Mesolithic for its formation. However, the contextual security of this lithic is dubious, given the history of ploughing and other disturbance at the site. About $3 \mathrm{~m}$ to the north of the features, a modern ditch (023) that runs to a nearby septic tank crossed the trench.

The ploughsoil (001) in Trench 3 sealed several features cut into the orange silty sand subsoil (004) (plan, Illus 15).

Two linear features (020 and 022), sharing a roughly north/south alignment and with their ends 


\section{Trench 1 Sections

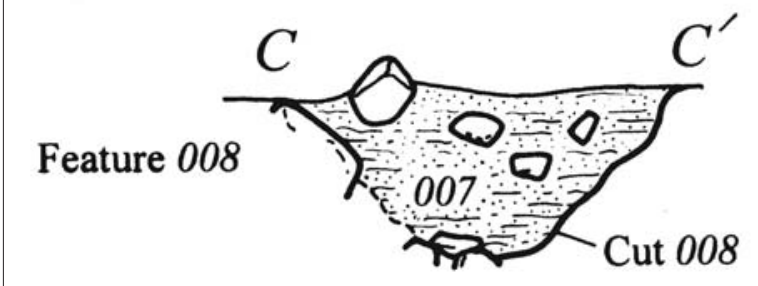

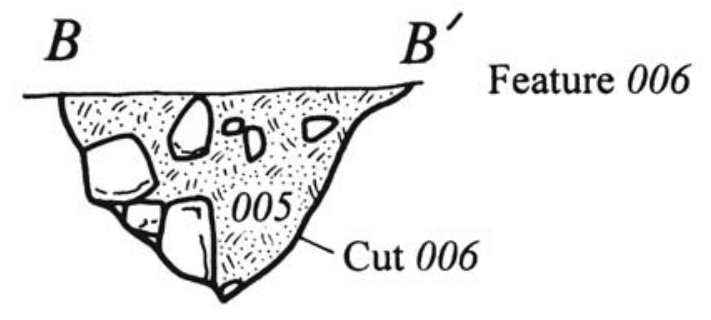
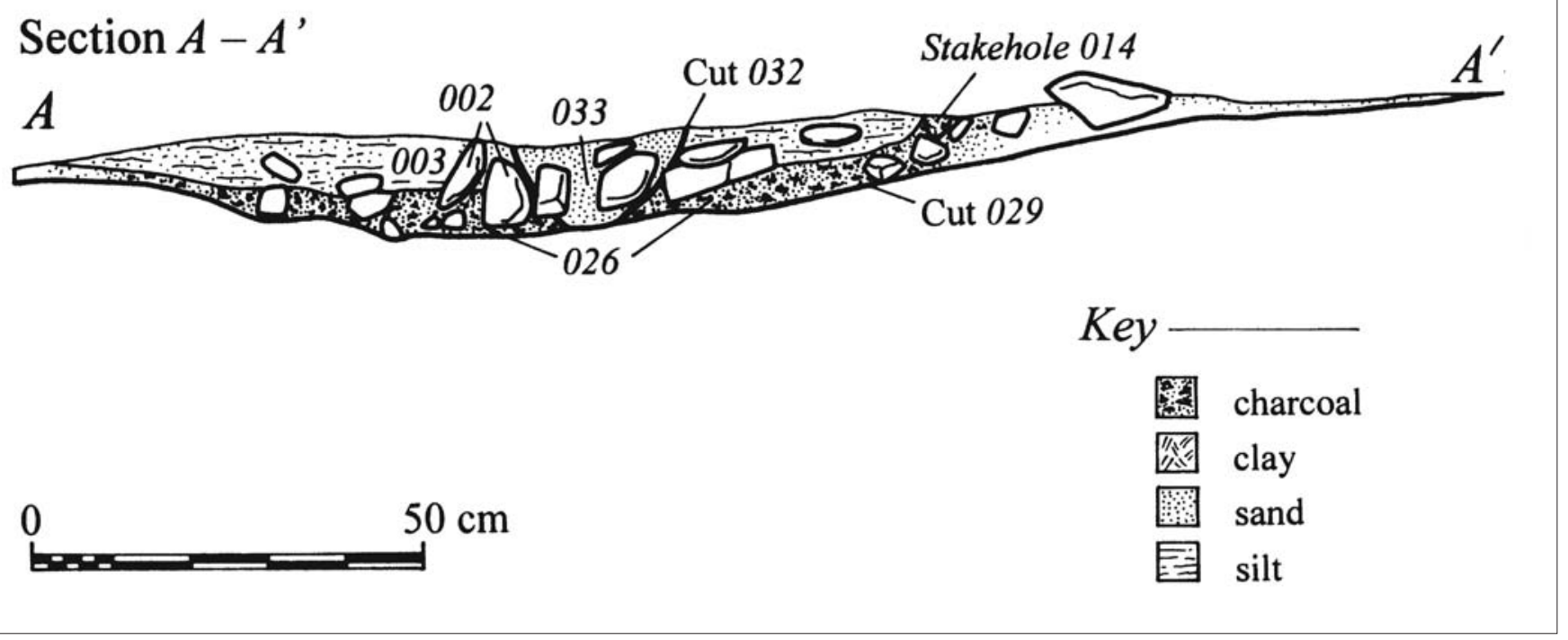

Illus 14 Trench 1 sections

separated by a gap of just under $2 \mathrm{~m}$, entered the trench from either side.

The eastern feature (020) extended south into the trench for $1.9 \mathrm{~m}$ from its north side, curving slightly along its length with a rounded southern terminal. It had an open U-shaped profile and was $0.2 \mathrm{~m}$ deep at the centre, with stones packed into the light orangepink fine sand (019) of its fill. The other feature (022) extended $0.8 \mathrm{~m}$ northward into the trench from the opposite side with a tapered northern terminal. Excavation of half of its visible length showed the terminal sloped down in a steep step to a relatively flat base, $0.18 \mathrm{~m}$ deep; the ditch was filled with light orange-pink fine sand with lenses of clean greywhite sand (021). These two features were interpreted as a pair of associated ditches, perhaps forming the entrance to a ring-ditch enclosure, although the size of the trench precluded definitive interpretations.

Between the two putative ditches, a small, oval deposit of charcoal-rich silt (025) lay in a slight hollow in the subsoil. This may have been an extremely truncated post or stake hole, the contents of which had burnt.

Across the southern part of Trench 3, extending eastward from the southern putative ditch terminal (022), was a spread of light pink-brown, fine sand (context 030) with charcoal flecks (not excavated). A small sherd of pottery was recovered from its surface beside the terminal.

The pot sherd (sf no M611) measures a maximum of $30 \times 23 \mathrm{~mm}$ and is $12 \mathrm{~mm}$ thick. It is a body sherd, with a noticeable curve despite its small size. Its fabric is reasonably hard and slightly sandy. Although mineral accretions partly mask the firing profile, it appears to be oxidized on the exterior and reduced on the interior, with what may be traces of an oxidized slip on the interior. Four parallel rows of fine comb impression are visible on the exterior. The sherd's curve suggests it came from the shoulder of the vessel, while the decoration indicates that the vessel was a Beaker. While the uncertainties that now plague Beaker chronologies (Kinnes et al. 1991) make its dating uncertain, it is likely to date from the mid 3rd millennium into the 2nd millennium BC (Sheridan 1997, 223).

The trial trenching, although limited in scale, did establish the presence of significant archaeological features beneath the densest concentration of lithics identified during field walking. These features appear to include a late Mesolithic knapping floor; a hearth, either respected or superseded by a postbuilt structure, and a pair of associated ditches, possibly representing a ring-ditch. 

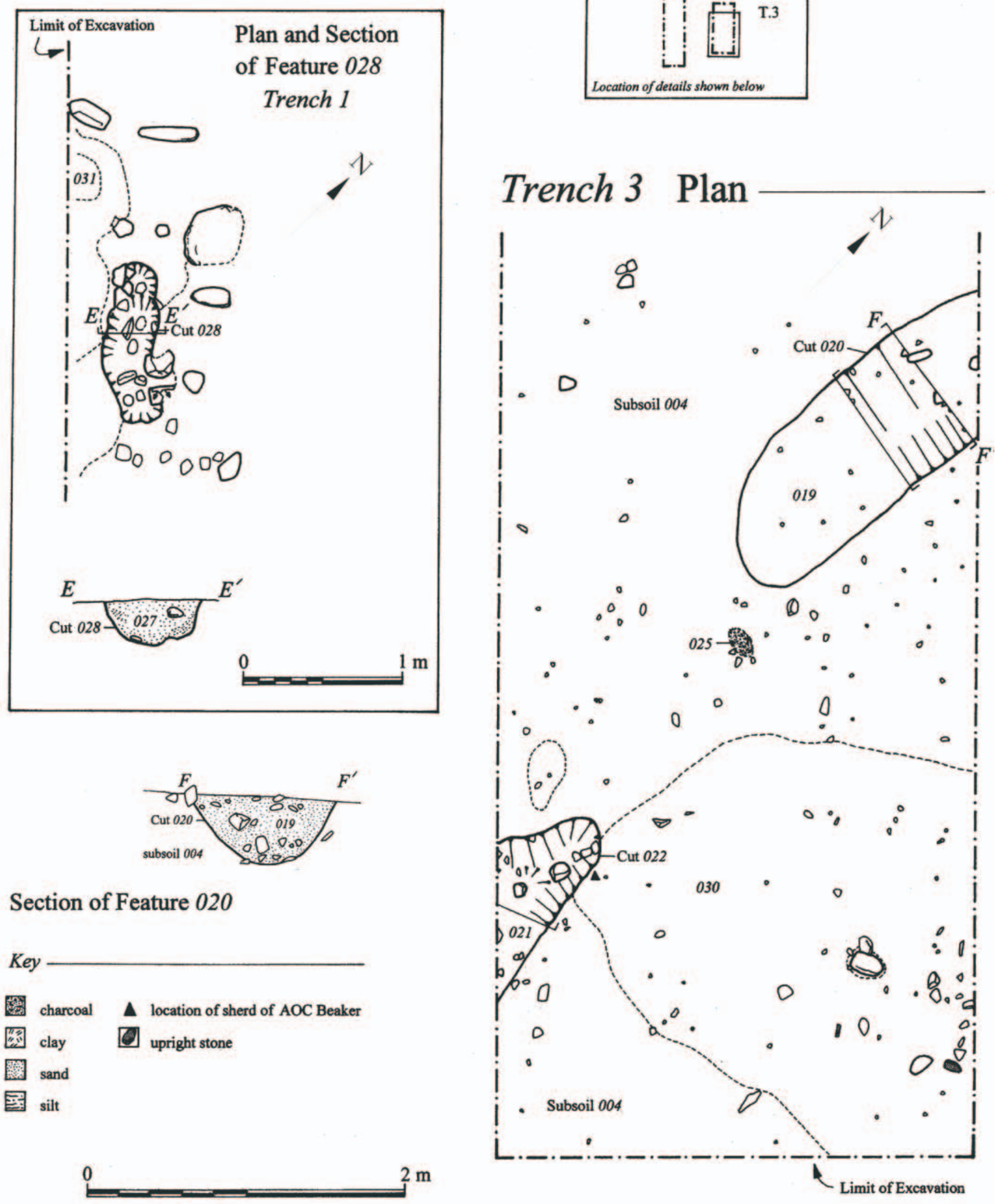

\section{Section of Feature 020}

Key
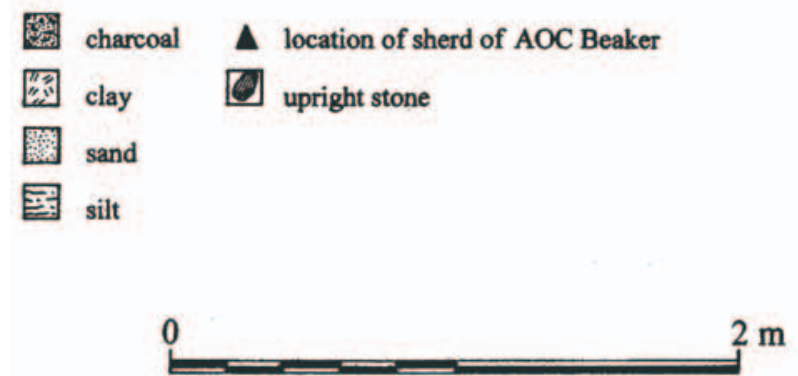
$2 \mathrm{~m}$ Location of details shown below

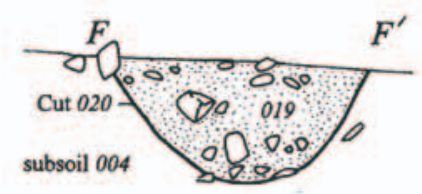


The results of the lithic analysis (Section 5.2.1) indicated an intensive phase of activity at Carmichael, including tool production, in the late Mesolithic, with a less intensive phase of tool production, use and abandonment at the end of the Neolithic and into the Bronze Age. This interpretation accords with the archaeological remains uncovered. The possible ring-ditch might represent the last phase of use in the Bronze Age and would suggest the presence of a ceremonial monument at the site. 


\section{Discussion by $O$ Lelong}

This section first sets the lithic scatters in the context of other scatters in the region. It then summarizes the project's findings and draws attention to the questions raised and the patterns identified in the prehistoric landscape as a result.

\subsection{The lithic scatters in context by $C$ Barrowman}

Information contained in the Scottish Lithic Scatters Database (Barrowman 2000b; Barrowman \& Stuart forthcoming) was used to set the lithic scatters recorded on the Carmichael Estate (Section 5.2.1) in the context of other scatters in the vicinity.

The fertile soils of South Lanarkshire have produced a large number of lithic scatters. Many of these were discovered in the first part of the 21st century, with some findings in the 1960s, but the majority were recorded more recently by the Lanark and District Archaeological Society. The highest concentration of scatters in the area lies in an amorphous strip approximately 10 miles wide, running from the southern slopes of the Pentland Hills in the north to the Southern Uplands in the south. The area upon which the following discussion focuses lies on the western edge of this concentration (covered by National Grid squares NS 93 and 94).

Twenty-five scatters, five of which are single, isolated finds, were recorded (as of 1999) in the Scottish Lithic Scatters Database for this area. The majority of these scatters are small (consisting of between two and 49 lithics) and discrete.

Chert dominates these scatters, with flint also present in smaller quantities; one pitchstone piece came from Annieston (NGR NS 992 375) to the south-east of the Pettinain Uplands. Investigation of sand and gravel workings at Annieston by M Brown in 1988 revealed this small scatter, which included a barbed and tanged arrowhead, worked flint and chert flakes and Neolithic pottery sherds. This may represent the remains of a later prehistoric settlement, although the site was too disturbed to characterize with confidence.

Chert flakes and cores were also recovered from Broadfield Farm (NS 990 335) by H M and D MacFadzean in 1984, along the River Clyde to the south-east of Tinto Hill. A few metres away a scatter of small worked flakes of chert and flint were recorded by the same field walkers, again from sand and gravel workings (NS 987 334). Further south along the river at Lamington, quartzite and flint debris were recorded by Archer and Brown in 1988; these remains have been described as Neolithic (NS 977 307).
Closer to Blackshouse Burn, a small scatter of chert flakes was found on Cairngryffe Hill during field walking over land ploughed for forestry (NS 943 417) in 1989 by $\mathrm{P}$ and $\mathrm{J}$ Taylor. No period has been assigned to these lithics, although it is assumed they indicate working in the immediate area.

Diagnostic tools such as scrapers have been recorded in three previous instances: one at Law Farm (NS 9838 found by W A Munro in 1962) to the south-east of the Pettinain Uplands, and two in the immediate vicinity at Thankerton (NS 98043820 found by M Brown in 1988, and NS 982377 found by $\mathrm{H}$ MacFadzean in 1984). The first three artefacts may belong to the same scatter and appear in the Database as isolated finds only because of their separate dates of discovery. In many cases, only diagnostic lithics have been recorded by field walkers, although other less obviously worked pieces may have been present.

Several additional scatters have been recorded as entries in Discovery and Excavation in Scotland since the completion of the Scottish Lithic Scatters Database in 1999. Among them are a cluster of lithics on Brownsbank Farm, near Biggar, which included pitchstone and flakes of type VI axes along with early Neolithic pottery (Ward 2001). Another scatter was discovered more recently at The Sills in Pettinain parish; this consisted of a small but dense cluster of struck chert, flint and pitchstone, thought perhaps to indicate a knapping site (Fawell 2002).

Although the scatters described above constitute only a small proportion of those known in the area, the overall distribution of the remaining ones suggests that they were discovered through field walking the arable stretches along the River Clyde, from Castledykes to the north-west of Blackshouse Burn (NS 92 44), through Bagmoors to the east (NS 95 43) and following the river's course as it winds around the Pettinain Uplands southward to Thankerton (NS 97 37), Annieston (NS 99 37), Broadfield (NS 99 33) and to the south of Tinto Hill as far as Lamington (NS 97 31).

It is assumed that some bias has resulted from selective field walking of ploughed areas, and that this pattern does not reflect the true distribution of prehistoric activity. Certainly the majority of the scatters have been recovered from arable fields, with only one fifth coming from forestry ploughing and upland areas. This bias toward finds on arable lands prevails throughout Scotland and is inherent in the nature of scatters, as they are most commonly created by ploughing.

It must also be noted that a scatter found and recorded by any field walker almost certainly does not fully represent the actual lithic contents of a 
field. Lithic scatters consist of material which has been disturbed and moved by the plough. These disturbed lithics may indicate the locations of in situ concentrations, as in Field M at Carmichael, but this can only be proved through further work such as geophysical survey and ultimately excavation.

Nevertheless, surface scatters are relatively good indicators of the spread of past human activity across the landscape. The simplest of activities, such as knapping a core, will leave a material mark, although it may have lasted no more than a few minutes. The larger scale examination of the landscape around the Blackshouse Burn monuments has revealed traces of such events in greater and lesser concentrations, and those in Field $\mathrm{M}$ at Carmichael have been shown to be related to surviving archaeological features in and on the subsoil. As such, the work has expanded our understanding of the archaeological resource in the Upper Clyde Valley.

\subsection{The upland monument surveys}

The topographic and geophysical surveys of the upland monuments have raised certain interpretations and questions that could be tested through future investigation, in addition to creating a digital record of the remains and their topographic settings.

In particular, the Blackshouse Burn monument geophysical survey revealed evidence for an entrance to the smaller enclosure and a linear feature linking it to the larger one; however, both of these anomalies could have been created by plough disturbance, as they run in the same direction as plough marks to the west. The resistivity survey also confirmed the staggered nature of the large enclosure's terminals at its western entrance and revealed a possible stone-edged pond and a curvilinear feature in the interior. The magnetic survey recorded a string of dipolar anomalies that may indicate the former presence of a screen that would have exaggerated the angle of the entrance and channelled movement southwards into the enclosure. The possible interpretations raised by these results could be tested through excavation in future.

The results of the Chester Hill survey recorded the extent of former planting on the monument and the form and condition of the earthworks, while the geophysical surveys revealed further details of the curvilinear depression concentric with most of the monument's inner bank. This was interpreted either as a series of contiguous quarry scoops or as an internal ditch. Because the anomaly continues across the western entrance and is interrupted on the south, it has been suggested that the bank was originally broken on the south and that the western entrance is not original. Alternatively, it is possible that the possible internal ditch or series of quarry scoops is a later feature, relating to refurbishment or augmentation of the inner bank. The geophysical surveys at Chester Hill also revealed what may be the traces of internal structures, although any archaeological deposits associated with them may be severely compromised by tree roots.

Chester Hill has been interpreted as a fort (RCAHMS 1978, 97, no 224), presumably because of its hilltop position and its double banks and medial ditch. While in area it is within the range of the other 27 monuments interpreted by the Royal Commission as forts in South Lanarkshire, only three including Chester Hill are circular.

In its form and dimensions, Chester Hill is very similar to the monument at Craigie Burn, Libberton (RCAHMS 1978, 97, no 291 and plate 15A), about $4 \mathrm{~km}$ to the north-east, which was subject to geophysical survey under the auspices of the Upper Clyde Valley Landscape Project (Hanson \& Sharpe in prep; Sharpe forthcoming). While not set on a hilltop, the earthwork does occupy a plateau overlooking the River Clyde (L Sharpe, pers comm). Craigie Burn has been interpreted as a henge, although some doubt about its classification is reflected in the CANMORE entry for the site (NMRS NS94SE19).

While these similarities do not necessarily mean that Chester Hill is a henge or Craigie Burn a hillfort, they do highlight the coarse resolution of some of our archaeological categories and the need for more informed interpretation of monuments in the region. The results of field walking on the lower slopes of Chester Hill recovered quantities of mixed earlier prehistoric material which may have moved downslope from their original place of deposition, perhaps on the summit of the hill. It is possible that either the present monument or a predecessor formed part of the early prehistoric ritual complex on the Pettinain Uplands.

The survey of the archaeological remains on Cairngryffe Hill recorded a coherent settlement of likely prehistoric date, consisting of hut circles and associated field systems, that may be contemporary with some of the later burial cairns on the uplands. It also recorded the presence of post-medieval sheep management features and associated cart trackways, overlain on the prehistoric landscape. The Swaites Hill survey also recorded prehistoric agricultural settlement remains, as well as what may be a ring cairn on its summit.

The surveys also recorded several potential and active management problems. At Chester Hill, sheep and cattle entering the enclosure and sheltering under the trees are severely eroding the banks in several places; rabbit burrows are also causing damage to the banks and interior. At Blackshouse Burn, the use of heavy vehicles across the large enclosure's bank was also damaging it at the time of survey, although the same route appeared to be used consistently and so the damage was not widespread. The western edge of the monument on the summit of Swaites Hill was also being encroached upon by a well-used farm track. Of all these fragments of prehistoric landscape, some statutory protection through scheduling is extended to the Blackshouse Burn enclosures (SAM 4063), the nearby enclosure of 
Meadowflatts (SAM 4068) and the summit of Chester Hill (SAM 2598), as of January 2004.

\subsection{Prehistoric activity on the lower slopes and in the valleys}

The field walking programme in the valleys to the south and west of the Pettinain Uplands identified several significant clusters of lithic material.

Lithics indicating activity in the early Mesolithic were sparse but nevertheless significant. A diffuse scatter of material from this period was found in the small valley to the west of the Pettinain Uplands (Field D), which is transected by the Blackshouse Burn.

Lithics dating from the late Mesolithic found elsewhere in the survey area could be contemporary with the phases of pre-monument activity around Blackshouse Burn, identified through pollen analysis of the upland peat deposits. That activity perhaps involved hunting and vegetation clearance (Ramsay 1998).

The most significant cluster, at Carmichael (Field M), indicated both tool production and use. Trial trenching over the scatter revealed a late Mesolithic knapping floor. A nearby hearth scoop and a line of post holes, possible evidence of a windbreak or cooking frame, could be associated with the knapping floor. These could be the remnants of a camp site.

At Garvald Burn in Tweeddale, excavation over a lithic scatter revealed a knapping floor, a hearth and several post and stake holes (Barrowman 2000a; Barrowman forthcoming). Although the lithics suggested a late Mesolithic date for the knapping floor, charcoal from the hearth yielded four radiocarbon dates centred on the mid 4th millennium BC (eg GU 10415: 3940-3630 cal BC at 95.4\% probability).

Within the survey area, evidence of late Mesolithic to early Neolithic tool production was also recovered from the field to the south of Chester Hill (Field N). The tiny pitchstone flake found in the valley transected by the Blackshouse Burn (Field D) shows that there was some kind of exchange or contact between people here and on the Island of Arran, most likely in the early Neolithic.
Lithics from the late Neolithic to early Bronze Age were found in more abundance: at the edge of the uplands adjacent to the Blackshouse Burn monuments (Fields A/B); in the valley to the west of the monuments (Field D), where a zone of tool or blank production and a zone of tool use and/or discard were identified; on the lower southern slopes of Chester Hill (Fields $\mathrm{G}$ and $\mathrm{H}$ ), where the tools found might have moved downslope from their place of deposition; and in the valley of the Glade Burn (Field K), as evidence of late Neolithic tool production.

At Carmichael (Field M), the dense late Mesolithic cluster associated with the knapping floor also contained lithics indicating tool production and use in the late Neolithic to early Bronze Age, although at a lower level of intensity.

The field walking demonstrated that the early and late Mesolithic material was concentrated in the valley bottoms, while the late Neolithic to early Bronze Age lithics were also found on the lower slopes and at the edge of the uplands. Although the sample size was small, this suggests that the late Neolithic saw more sustained activity on the slopes and onto the uplands. That activity involved both tool production and use, perhaps relating to permanent or seasonal settlements.

Trial trenching corroborated the evidence of the late Neolithic to early Bronze Age lithics at Carmichael (Field M), yielding a sherd of late Neolithic Impressed Ware and one of Beaker. The two ditch terminals discovered could belong to a ring-ditch, perhaps indicating the presence of a ceremonial or burial enclosure at the site in the Bronze Age, with which the Beaker sherd may have been associated. It is also possible that the line of post holes was associated with the putative ring-ditch rather than with the hearth scoop.

The evidence from Carmichael does suggest that the same place was a focus for activity over several millennia, in the late Mesolithic, late Neolithic and early Bronze Age. The later phases of activity here would have been contemporary with the construction and use of the ceremonial monuments on the uplands, particularly those at Blackshouse Burn and Cloburn Quarry. 


\section{Conclusions from the Blackshouse Burn Environs Project by $O$ Lelong}

The results of the Blackshouse Burn Environs Project, in tandem with other recent work including the excavations on Biggar Common (Johnston 1997) and that of the Upper Clyde Valley Landscape Project (Hanson \& Sharpe in prep; Sharpe forthcoming), have shown the enormous potential of the valley's landscape for yielding evidence of its early prehistoric occupation. The evidence so far indicates that that activity may have taken place continuously or intermittently over several phases, spanning millennia, at the same sites. The fieldwork has demonstrated the great value of lithic scatters in the area as indicators of the presence of sub-surface, multi-phased archaeological remains.

A number of sites now have produced evidence for later Mesolithic and early or late Neolithic activity on the same spot, at various scales. These include the Blackshouse Burn monuments, with late Mesolithic vegetation clearance and perhaps hunting preceding the late Neolithic monument construction; Biggar Common, with a late Mesolithic structure on the same site as early Neolithic bonfires and an earthen mound, and later Neolithic to Bronze Age mortuary activity; and Carmichael, with a late Mesolithic knapping floor and possibly associated hearth, evidence of late Neolithic to early Bronze Age tool production and use, and possibly ceremonial activity in evidence through the pottery and putative ring-ditch.

Some such instances of the multi-phased use of the same site may be purely coincidental; however, it is unlikely that all were. If some were deliberate, then certain places in the Upper Clyde Valley must have held their significance over thousands of years. Murray has argued that earlier Neolithic ceremonial activity and the construction of monuments on sites that were significant in the Mesolithic (as seems to have happened on Biggar Common) may have expressed a cultural and cognitive transformation (Murray 2000). This transformed mindset, she argues, would have been a deliberate and necessary precedent to the fundamental economic shift toward domestication. It has been suggested that the construction of the late Neolithic enclosure at Blackshouse Burn - an architectural intervention on an enormous scale - was only possible after people had begun to re-order the natural world as a matter of course, through domestication, and that its construction formally expressed a long-standing relationship with the place (even if the nature of its significance had changed over time) (Lelong \& Pollard 1998a, 47-50).

The late Neolithic saw the construction of a number of large ceremonial enclosures like the Blackshouse Burn enclosures in agriculturally productive areas like the Upper Clyde Valley and elsewhere in south-east Scotland - for instance, at Meldon Bridge, Peebleshire (Speak \& Burgess 1999). Their construction may have been linked, as Telford has suggested, to the emergence of social hierarchies (Telford 2002, 306-310), itself motivated by the desire to increase arable yields through the centralized organization of labour.

Enclosures such as those at Blackshouse Burn may have been built as regional gathering places for groups across the area, in the way that smaller henges perhaps were used on a more local scale. Future fieldwork, particularly field walking and trial excavation of lithic scatters, should steadily increase our understanding of the locations and nature of contemporary settlement and of the people who built, gathered in and buried their dead at the ceremonial monuments. 


\section{Memoriam to Jerry Hamer 1950-2001}

Just one of many projects in which Jerry participated during his career as a talented geophysical surveyor, the Blackshouse Burn Environs Project took place during some of the most atrocious winter weather that any of us had seen. As always, Jerry kept spirits and working standards high throughout, and everyone who worked with him respected and admired him. He is and will remain a valued and deeply missed friend and colleague, one who - through his skill, dedication and sense of humour - enhanced any work in which he was involved. He will always be in our minds, especially when we are in the field. 


\section{Acknowledgements}

This project was funded by Historic Scotland. Thanks are extended to Andrea Smith of Historic Scotland, who monitored the project and provided encouragement and support throughout; Roderick McCullagh, who saw the report through its final stages and provided useful comments; and the SAIR referees, who also improved the report's content through their comments. Richard and Trish Carmichael of Carmichael kindly permitted access to ploughed fields and monuments on the Carmichael estate, and Robert Black of Meadowflatt Farm allowed access to part of the Blackshouse enclosures and to the Meadowflatts enclosure.

Thanks are also extended to those who participated in the various phases of the fieldwork: Janet Hooper and Stuart Halliday, who assisted with the topographic survey; Kirsteen McLellan, Helen
Saunders, Mike Davies and Prabakar Sri Ranganathan, who assisted with the geophysical survey; and Scott Coulter, Mary Craig, Natasha Davidson, Stuart Graham, Mirko Gutjahr, Erica Hanning, Frigga Kruse, Mike Malamos, Gert Petersen, Lyndsay Trann and Paul White, who assisted with the field walking and the trial excavation. The project was managed for GUARD by Heather James. Caitlin Evans produced illus 1 and 13-15, while John Arthur finalized the survey drawings.

As regards the project archive, all written and drawn records and electronic data will be lodged with the National Monuments Record of Scotland; the location of finds will be determined by Historic Scotland's Finds Disposal Panel. The finds from the 1985-86 excavations at Blackshouse Burn were allocated to Biggar Museum Trust. 


\section{References}

Aitken, M J 1961 Physics and Archaeology. New York.

Barrowman, C S 2000a 'Garvald Burn, Scottish Borders (Garvald parish), late Mesolithic chert scatter and knapping floor', Disc Excav Scotland 2000, 77-8.

Barrowman, C S 2000b Lithic Scatters as an Archaeological Resource in South and Central Scotland. Unpublished PhD thesis, University of Glasgow.

Barrowman, C S forthcoming Garvald Burn Lithic Scatter.

Barrowman, C S \& Stuart, E forthcoming Scottish Lithic Scatters Project.

Bradley, R 1991 'Monuments and places', in Garwood, P, Jennings, D, Skeates, R \& Toms, J (eds) 1991 Sacred and profane: Proceedings of a conference on archaeology, ritual and religion (Oxford 1989). Oxford, 135-40.

Burgess, C 1976 'Meldon Bridge: a Neolithic defended promontory complex near Peebles', in Burgess, C \& Miket, $\mathrm{R}$ (eds) Settlement and Economy in the Third and Second Millennia $B C, 151-79$. Oxford [= Brit Archaeol Rep Brit Ser 33].

Christison, D 1890 'Forts, camps and motes of the Upper Ward of Lanarkshire,' Proc Soc Antiq Scot 24, 281-352.

Childe, V G 1941 'Examination of the prehistoric fort on Cairngryffe Hill, near Lanark', Proc Soc Antiq Scot 75, 213-18.

Clough, T H McK \& Cummins, W A 1988 Stone Axe Studies, vol 2. London [ = CBA Res Rep 67].

Donnelly, M 1998 'Garvald Burn lithic scatter catalogue', unpublished lithic report.

Downes, J 2001 'The investigation of a Bronze Age cairnfield and later buildings at Fall Kneesend, Clydesdale', Scot Archaeol J 23.1, 33-66.

Fawell, K 2002 'The Sills (Pettinain parish)', Disc Excav Scotland 2002, 114.

Ferguson, J 1794 'Parish of Pettinain', in Sinclair, J (ed), The Statistical Account of Scotland, Vol 12, Edinburgh, 28-42.

Finlayson, B 1990 'The function of Microliths, evidence from Smittons and Starr, SW Scotland', Mesolithic Miscellany, 11.1, 2-6.

Hanson, W S \& Sharpe, L in prep The Upper Clyde Valley Landscape Project.

Johnston, D A 1997 'Biggar Common, 1987-93: an early prehistoric funerary and domestic landscape in Clydesdale, South Lanarkshire', Proc Soc Antiq Scot 127, 185-254.

Kinnes, I, Gibson, A, Ambers, J, Bowman, S \& Boast, R 1991 'Radiocarbon dating and British Beakers: the British Museum programme', Scot Archaeol Rev 8, 35-68.
Lelong, O \& Pollard, T 1998a 'The excavation and survey of prehistoric enclosures at Blackshouse Burn, Lanarkshire', Proc Soc Antiq Scot 128, 13-53.

Lelong, O \& Pollard, T 1998b 'Excavation of a Bronze Age ring cairn at Cloburn Quarry, Cairngryffe Hill, Lanarkshire', Proc Soc Antiq Scot 128, 105-142.

MacGregor, $\mathrm{G}$ forthcoming 'Excavations at Fox Plantation, Dumfries and Galloway, 1995 \& 1996', in Brophy, K, James, H \& Ballin-Smith, B (eds) The Results of Archaeological Excavations During Construction of the Scotland to Northern Ireland Gas Pipeline 1995 to 1997.

MacGregor, G \& Donnelly, M 2001 'A Mesolithic scatter from Littlehill Bridge, Girvan, Ayrshire', Scot Archaeol J 23.1, 1-14.

Murray, J 2000 'Peau noire, masques blancs: self-image in the Mesolithic-Neolithic transition in Scotland', Antiquity 74, 779-785.

Ness, J \& Ward, T 2001 Pitchstone Seminar, held 30th September 2000. Biggar Museum Trust report.

Ramsay, S 1998 'Pollen analysis', in Lelong, O \& Pollard, T 1998b 'Excavation of a Bronze Age ring cairn at Cloburn Quarry, Cairngryffe Hill, Lanarkshire', Proc Soc Antiq Scot 128, 37-40.

Ross, L 1999 'Excavations at Burnhouse Moor, Clydesdale, 1985', Glasgow Archaeol Soc 21, 15.

RCAHMS 1978 Lanarkshire: An Inventory of the Prehistoric and Roman Monuments. Edinburgh.

Sharpe, L forthcoming 'An integrated approach to landscape investigation: case studies in the Upper Clyde Valley', in Carver, E \& Lelong, O (eds), Modern Views - Ancient Lands: New Work and Thought on Cultural Landscapes, Oxford.

Sheridan, A 1989 'Biggar Common (Biggar Libberton parish), round cairn, long mound, surface scatter', Disc Excav Scotland 1989, 41.

Sheridan, A 1997 'Pottery', in Johnston, D A 1997 'Biggar Common, 1987-93: an early prehistoric funerary and domestic landscape in Clydesdale, South Lanarkshire', Proc Soc Antiq Scot 127, 202-223.

Speak, S \& Burgess, C 1999 'Meldon Bridge: A centre of the 3rd millennium BC in Peebleshire', Proc Soc Antiq Scot 129, 1-118.

Stevenson, J 1976 'A short cist from the Hero's Cairn, Lanarkshire', Proc Soc Antiq Scot 107, 299-301.

Telford, D 2002 ‘The Mesolithic inheritance: 
contrasting Neolithic monumentality in Eastern and Western Scotland', Proc Prehistoric Soc 68, 289-315.

Terry, J 1995 'Excavation at Lintshie Gutter unenclosed platform settlement, Crawford, Lanarkshire, 1991', Proc Soc Antiq Scot 125, 269-427.

Ward, T 1990 'Biggar Common (Biggar parish), surface lithics, pottery, cairns', Disc Excav Scotland 1990, 37.

Ward, T 1991a 'Biggar Common (Biggar parish): Neolithic structure and finds', Disc Excav Scotland 1991, 66.

Ward, T 1991b 'Survey: A74 and M74 road development routes', Disc Excav Scotland 1991, 65.

Ward, T 1992 'Biggar Common (Biggar parish): Neolithic artefact scatters', Disc Excav Scotland 1992, 65.

Ward, T 1993 'Biggar Common (Biggar parish): Neolithic/Bronze Age artefact scatters', Disc Excav Scotland 1993, 87.
Ward, T 1995 'Biggar Common (Biggar parish), Neolithic settlement date', Disc Excav Scotland $1995,87$.

Ward, T 1998 'Glenochar Bastle House and Fermtoun'. Lanark and District Archaeological Society.

Ward, T 2001 'Brownsbank Farm, Biggar (Biggar parish)', Disc Excav Scotland 2001, 90.

Ward, T \& Brown, M 2001 Results of a Pre-afforestation Survey Commissioned by Scottish Woodlands Ltd at Dyke Farm, Straiton, Carrick North Ward, Ayrshire. Biggar Museum Trust unpublished report.

Williams Thorpe, O \& Thorpe, R S 1984 'The distribution and sources of archaeological pitchstone in Britain', J Archaeol Sci 11, 1-34.

Zetterlund, P \& McCartan, S 1990 'The lithic assemblage: secondary technology', in Wickham-Jones, C R Rhum: Mesolithic and Later Sites at Kinloch, Edinburgh, 87-102 [= Soc Antiq Scot Monograph 7]. 